\title{
Toxicity and Safety Evaluation of Doxorubicin-Loaded Cockleshell-Derived Calcium Carbonate Nanoparticle in Dogs
}

\author{
Abubakar Danmaigoro (D), ${ }^{1,2}$ Gayathri Thevi Selvarajah $\left(\mathbb{D},{ }^{3}\right.$ Mohd Hezmee Mohd Noor (iD), \\ Rozi Mahmud, ${ }^{4}$ and Md Zuki Abu Bakar $\mathbb{D}^{1}$ \\ ${ }^{1}$ Department of Veterinary Preclinical Science, Faculty of Veterinary Medicine, Universiti Putra Malaysia, 43400 Serdang, \\ Selangor Darul Ehsan, Malaysia \\ ${ }^{2}$ Department of Veterinary Anatomy, Faculty of Veterinary Medicine, Usmanu Danfodiyo University, P.M.B. 2346, \\ Sokoto, Nigeria \\ ${ }^{3}$ Department of Veterinary Clinical Studies, Faculty of Veterinary Medicine, Universiti Putra Malaysia, 43400 Serdang, \\ Selangor Darul Ehsan, Malaysia \\ ${ }^{4}$ Department of Imaging, Faculty of Medicine and Health Science, Universiti Putra Malaysia, 43400 Serdang, \\ Selangor Darul Ehsan, Malaysia \\ Correspondence should be addressed to Md Zuki Abu Bakar; zuki@upm.edu.my
}

Received 15 January 2018; Revised 17 March 2018; Accepted 30 April 2018; Published 24 June 2018

Academic Editor: Paola Patrignani

Copyright ( 92018 Abubakar Danmaigoro et al. This is an open access article distributed under the Creative Commons Attribution License, which permits unrestricted use, distribution, and reproduction in any medium, provided the original work is properly cited.

\begin{abstract}
Doxorubicin (DOX) is a potent anticancer agent with cytotoxic effects which limit its clinical usage. This effect is due to its nonselective nature causing injury to the cells as a result of reactive free oxygen radical's release. Cockleshell-derived calcium carbonate nanoparticle ( $\left.\mathrm{CS}-\mathrm{CaCO}_{3} \mathrm{NP}\right)$ is a $\mathrm{pH}$-responsive carrier with targeted delivery potentials. This study aimed at evaluating the toxicity effects of repeated dose administration of DOX-loaded CS-CaCO${ }_{3} \mathrm{NP}$ in healthy dogs. Fifteen dogs with an average body weight of $15 \mathrm{~kg}$ were randomized equally into 5 groups. Dogs were subjected to 5 doses at every 3-week interval with (i) normal saline, (ii) DOX, $30 \mathrm{mg} / \mathrm{m}^{2}$, and the experimental groups: CS-CaCO ${ }_{3} \mathrm{NP}-\mathrm{DOX}$ at (iii) high dose, $50 \mathrm{mg} / \mathrm{m}^{2}$, (iv) clinical dose, $30 \mathrm{mg} / \mathrm{m}^{2}$, and (v) low dose, $20 \mathrm{mg} / \mathrm{m}^{2}$. Radiographs, electrocardiography, and blood samples were collected before every treatment for haematology, serum biochemistry, and cardiac injury assessment. Heart and kidney tissues were harvested after euthanasia for histological and ultrastructural evaluation. The cumulative dose of DOX $150 \mathrm{mg} / \mathrm{m}^{2}$ over 15 weeks revealed significant effects on body weight, blood cells, functional enzymes, and cardiac injury biomarkers with alterations in electrocardiogram, myocardium, and renal tissue morphology. However, the dogs given CS-CaCO $3 \mathrm{NP}-\mathrm{DOX} 150 \mathrm{mg} / \mathrm{m}^{2}$ and below did not show any significant change in toxicity biomarker as compared to those given normal saline. The study confirmed the safety of repeated dose administration of CS-CaCO${ }_{3} \mathrm{NP}-\mathrm{DOX}\left(30 \mathrm{mg} / \mathrm{m}^{2}\right)$ for 5 cycles in dogs. This finding offers opportunity to dogs with cancer that might require long-term administration of DOX without adverse effects.
\end{abstract}

\section{Introduction}

Doxorubicin (DOX) is one of the potent chemotherapeutic agents used in the management of both haematopoietic and solid malignant tumours of different origin [1-3]. In the past two decades, its application by oncologists has been extensively explored, although its continuous usage alone in clinical settings is impeded due to its life-threatening effect on organs such as heart, kidney, and liver $[4,5]$. DOX toxicity is generally inclined to the mitochondrial oxidative phosphorylation and calcium ion overload through multiple complex pathways $[2,6]$. The mitochondrial, sarcoplasmic reticulum, and nuclear material damages are due to the reactive oxygen radicals released during the biotransformation of DOX to semiquinone $[6,7]$ and a decrease in ATP synthesis [8]. This mitochondrial and genetic material disruption is believed to be positively correlated with the DOXinduced clinical cardiomyopathies $[9,10]$. 
Several efforts have recently been made to ameliorate the side effects of DOX $[2,11]$, with the use of lipids and assembled polymers in the delivery of DOX as seen in Doxil ${ }^{\mathrm{TM}}$ and Myocet $^{\mathrm{TM}}$ which are still associated with mild toxic effects on organs by eliciting proinflammatory cell release [12], with some other formulations shown having an increase in therapeutic efficiency with few setbacks, such as instability and biphasic release kinetic mechanism [13, 14]. However, decrease in toxicity was recorded with liposome conjugated with DOX in a mouse model, although the longtime cumulative effect of the liposome was not documented [15]. In addition, several organic macromolecules have been employed in nanomedicine for drug delivery $[16,17]$.

Thus, these growing interests in the use of nanocarrier in the delivery of anticancer with little or no accumulative toxic effects on tissue have encouraged the search for naturally occurring biogenic nanomaterials in drug delivery. DOX delivery using nanocarriers is advocated to reduce toxicity and improve therapeutic efficacy $[11,16]$.

Cockleshell-derived $\mathrm{CaCO}_{3}$ nanoparticle (CS-CaCO$\left.{ }_{3} \mathrm{NP}\right)$, an inorganic biodegradable drug carrier, has been used to deliver DOX and docetaxel in different experimental studies $[18,19]$. Despite the advances in cancer treatment, it still possesses significant threats to oncologists in using DOX in preventing cancer metastasis with its continuous usage hindered by its off-target effects on the proliferating healthy cells [20].

Previous studies indicate that electrocardiography and echocardiography are noninvasive techniques employed in monitoring cardiac injury, which are recommended in the evaluation of dogs undergoing chemotherapy [21, 22]. However, studies have shown that fractional shortening in echocardiography is associated with low specificity as a result of overreliance on preload and postload effect in dogs given DOX at several cyclic schedules [23]. As a result of these, other noninvasive assays are selected for the prediction of DOX-induced cardiotoxicity, such as serum cardiac muscle protein quantification specifically, cardiac troponin, and NT-pro-brain natriuretic peptides [24, 25], which are widely used in preclinical and clinical practices for cardiac injury detection.

The low therapeutic index of DOX has necessitated the search of targeted nanocarrier for DOX delivery in the treatment of solid cancer. $\mathrm{CS}-\mathrm{CaCO}_{3}$ nanocarrier conjugated with DOX has demonstrated control and slow release in both in vitro and in vivo studies in dogs [23]. However, there is lack of information on the toxicity and safety profile of the CS- $\mathrm{CaCO}_{3} \mathrm{NP}-\mathrm{DOX}$ upon repeated intravenous dose administration in dogs, which is needed to define the maximum tolerable dose (MTD) in dogs, which will serve as a key in attaining therapeutic success. In addition, the use of $\mathrm{CS}-\mathrm{CaCO}_{3} \mathrm{NP}$ to deliver $\mathrm{DOX}$ is to reduce its off-target effects through its $\mathrm{pH}$-responsive release mechanism. Hence, it is important to note that $\mathrm{CS}-\mathrm{CaCO}_{3}$ nanocarrier as compared to other commercially available synthetic polymers decomposes slowly in physiological state to produce $\mathrm{Ca}^{2+}$ and $\mathrm{CO}_{2}{ }^{3-}$ and release DOX for therapeutic purposes. The decomposed products could be useful in muscle contraction, bone remodelling, and blood clotting factor, whereas the carbonate component will be excreted through gaseous exchanges. Therefore, this study aimed at evaluating the toxicity and safety effects of repeated dose administration of CS-CaCO${ }_{3} \mathrm{NP}-\mathrm{DOX}$ in healthy dogs as an alternative carrier from inorganic biogenic source for the delivery of DOX with special interest on the cardiotoxicity and nephrotoxicity induced by DOX using biomarker, histopathology, and ultrastructural morphological changes for assessment.

\section{Materials and Methods}

2.1. Materials. Doxorubicin A.D. Mycin (Adriamycin ${ }^{\circledR}$ ) $50 \mathrm{mg} / 25 \mathrm{~mL}$ vial was purchased from Boryung Pharmaceutical Co. Ltd., Korea. 0.9\% normal saline, Canine NTproBNP (N-Terminal Pro-Brain Natriuretic Peptide) ELISA kit, and Canine cTn-I/TNNI3 (cardiac troponin I) ELISA kit (E-EL-C0212) were all purchased from the Elabscience, China, and were stored at $-20^{\circ} \mathrm{C}$. All other chemicals used were of analytical grade and were stored at $25^{\circ} \mathrm{C}$.

2.2. Synthesis of CS-CaCO${ }_{3} \mathrm{NP}$ and Incorporation of DOX into Synthesized $\mathrm{CS}-\mathrm{CaCO} \mathrm{C}_{3} \mathrm{NP}$. The synthesis, drug loading, and characterization of $\mathrm{CS}-\mathrm{CaCO}_{3} \mathrm{NP}$ and $\mathrm{CS}-\mathrm{CaCO}_{3} \mathrm{NP}-\mathrm{DOX}$ were carried out in accordance with the protocol and procedure developed by Danmaigoro et al. [26]. The synthesized $\mathrm{CS}-\mathrm{CaCO}_{3} \mathrm{NP}$ with a higher loading content capacity formulation was selected for DOX delivery.

\subsection{Repeat Dose Toxicity and Safety Studies in Healthy Dogs}

2.3.1. Animal Handling and Ethical Statement. A total of fifteen (15) healthy adult male local dogs (Canis lupus familiaris) aged 9-24 months, weighing 15-25 kg, were obtained from the Dewan Bandaraya Kuala Lumpur pound. Ages of the dogs were determined by dental recognition according to Iohara et al. [27] and from the dogs' records. Dogs were cleaned (bathe), detached using Bayticol ${ }^{\circledR}$ (Flumethrin), and dewormed with praziquantel $20 \mathrm{mg} / \mathrm{kg}$. The dogs were kept at $23 \pm 1^{\circ} \mathrm{C}$ for 12 -hour light and 12 hour dark cycle with access to feed and ad libitum water. All procedures involving animal care and handling according to the guidelines and approval of the Institutional Animal Care and Use Committee (IACUC) (UPM/IACUC/AUPRO13/2016), Universiti Putra Malaysia, and the recommendation of Canadian Council on Animals Care Guide to the Care and Use of Experimental animals were strictly followed [28, 29]. The dogs were confirmed clinically healthy by haematological evaluation, blood smear for heartworm, and physical screening, with no dogs placed on chemotherapeutic agent during the 2 -week period of acclimatization.

2.3.2. Exclusion and Inclusion Selection Criteria in the Study. Dogs with recognizable disease symptoms (vomiting, diarrhoea, cardiac murmur, or arrhythmia), bad temperament, or poor body condition score $(1 / 5)$ were excluded in the selection and enrolment into the experimental study. 
However, dogs with normal haematology and serum biochemistry parameters, healthy otherwise, good temperament, and good body condition score were selected and included in the study. Dogs were housed at the Animal Research Facilities (ARF), Faculty of Veterinary Medicine, Universiti Putra Malaysia.

2.4. Protocol. The dogs were randomly assigned to 5 groups $(n=3)$. Dogs were subjected to slow intravenous infusion $(0.9 \% \mathrm{NaCl})$ up to 5 doses every 3 -week interval with (i) normal saline $(0.9 \% \mathrm{NaCl})$ (negative control), (ii) DOX $30 \mathrm{mg} / \mathrm{m}^{2}$ (positive control), and the experimental groups: CS-CaCO ${ }_{3} \mathrm{NP}-\mathrm{DOX}$ at (iii) high dose, $50 \mathrm{mg} / \mathrm{m}^{2}$, (iv) clinical dose, $30 \mathrm{mg} / \mathrm{m}^{2}$, and (v) low dose, $20 \mathrm{mg} / \mathrm{m}^{2}$, in accordance with the DOX administration schedules. At day 0 (the first day of evaluation before administration of the first cycle), the data obtained from the sample serve as baseline values. All clinical and biological wastes from the studies were disposed according to the Veterinary Oncology guidelines with the use of anticancer agents as previously described by Théon et al. [30].

2.5. Physical and Clinical Observation. Daily physical, clinical signs against toxicity and mortality were observed. The body weight, rectal temperature, and heart rate were all measured as baseline and monitored twice weekly within the period of the study.

2.6. Sample Collection for Haematological Profile, Serum Biochemistry, and Cardiac Injury Biomarker Assay. Blood samples were collected in heparinized EDTA and plain tube for haematological profiling, serum function enzymes, and cardiac injury biomarkers, after 2 weeks of acclimatization period. Serial blood samples were collected once before each cycle. The samples were immediately analysed for complete blood count using Horiba Medical Scil Vet ABC Plus analyzer (Scil Vet. USA) with the whole blood centrifuged (Centrifuge Eppendorf 5424R, Germany) for 15 minutes at $4000 \mathrm{rpm}$, and the serum was stored at $-80^{\circ} \mathrm{C}$ for analysis. Function enzymes were analysed using Dimension Xpand Plus Integrated Chemistry System (Dimension ${ }^{\circledR}$ EXL $^{\mathrm{TM}} 200$ Integrated Chemistry System, Siemens, Germany) to evaluate the level of alanine transaminase (ALT), aspartate aminotransferase (AST), creatinine (Crea), blood urea nitrogen (BUN), creatinine kinase $(\mathrm{CK})$, and lactate dehydrogenase $(\mathrm{LDH})$ all according to the protocol described by Chang et al. [31].

\subsection{Cardiotoxicity Assessment Using Serum Biomarker.} Canine cardiac troponin I (cTn-I) and canine NT-pro-brain natriuretic peptide (Canine NT-proBNP) were used as major biomarkers for cardiac injury evaluation due to their selectivity and specificity to cardiac injury according to Cartwright et al. [32] and Sawaya et al. [33]. A sandwich ELISA method was adopted using Canine cTn-I/TNNI3 (canine troponin I) and Canine NT-proBNP (N-Terminal Pro-Brain Natriuretic Peptide) ELISA kit (E-EL-C0210) specific for serum samples collected from the dogs which were processed according to manufacturer's instructions and recommendations (Elabscience Biotechnology, Co., Ltd. China). The optical densities of each well on the microplate were read at $450 \mathrm{~nm}$ wavelength using spectrophotometer (Tecan Infinite 200 Pro microplate reader, USA).

2.8. Thoracic Radiographic Evaluation. An orthogonal view of the thoracic radiograph was exposed to radiographic system during inspiration as previously suggested by Gülanber et al. [34]. DRX-1 mobile radiography (Econet Orange $10040 \mathrm{HF}$ model Plus Carestream image system 3543C, USA) was used to evaluate the heart size using the vertebral heart score (VHS) as previously described by Surachetpong and Teewasutrakul [35]. These procedures were performed once at the beginning of the study and once at the end of the 3 weeks after the 5 th dose, with the both the long and short axes expressed in centimetres.

2.9. Electrical Conductivity and Cardiac Function Assessment Using Electrocardiography (ECG). Electrocardiograms were recorded in all the dogs before the commencement of the experiment to rule out cardiac dysfunction and cardiac chamber enlargements and were repeated at the end of the three weeks after the 5 th dose using the electrocardiographic system (Cardiofax GEM-9020K, Nihon, Japan) according to the protocol described by Alves de Souza and Camacho [36].

The electrodes were placed on the dogs in the standing position with crocodile clips placed on the skin just below the elbow joints and little above the stifle joint area with conducting medium added to enhance contact. The electrical activities of the heart were evaluated for the duration of 1 minute, with the paper speed of the ECG at $50 \mathrm{~mm} / \mathrm{sec}$, a voltage calibration scale of $1 \mathrm{~cm}$ equivalent to $1 \mathrm{mV}$, and $50 \mathrm{~Hz}$ filter, with the dogs manually restrained with insulated hands using gloves in the standing position devoid of panting, muscular tremor, and shaking, and at least 3 QRS complexes were recorded on the traces.

Heart rate, waves, intervals, duration of $\mathrm{P}$ wave, $\mathrm{PR}$ interval, QRS complex, and QT interval, and P wave amplitudes were recorded. However, $20 \%$ increase or decrease from any of the ECG parameters as compared to the pretreatment value obtained was considered alteration due to the intervention as previously reported by Mauldin et al. [37].

2.10. Euthanasia, Postmortem Examination, and Morphometry. The dogs were euthanized 3 weeks after the 5 th last dose. Carcasses were subjected to postmortem examination. The heart and kidney were removed with the relative heart weight measured. An incision was made between the papillary muscles and chordal tendon to expose both left and right ventricle walls and the interventricular septum. The ventricle wall thickness was measured in millimetre using a vernier caliper with the relative heart weight calculated by a formula adopted from Fracasso et al. [38]: 


$$
\begin{aligned}
& \text { Relative organ weight }(\mathrm{g} / \mathrm{kg}) \\
& =(\text { heart weight }(\mathrm{g}) / \mathrm{body} \text { weight }(\mathrm{kg})) * 100 \text {. }
\end{aligned}
$$

2.11. Histopathology Analysis. The heart (left and right ventricular walls and interventricular septum) and kidney tissues were fixed in $10 \%$ buffered formalin and processed for histological evaluation as described by Schäfer-Somi et al. [39]. The blocks were sectioned to approximately $4 \mu \mathrm{m}$ in size with a microtome (Leica 2235 Microtome, USA) and then finally, stained with Harris's haematoxylin and eosin and Masson's trichrome for histochemistry and examined under the light microscope (Leica DM4M, NY USA), with Moticam Pro 282A 5.0MP (Motic images Software Plus 2.0 TWAIN, Hong Kong). The degree of tissue injury, necrosis, and inflammatory response were evaluated using qualitative and semiquantitative grading system by a pathologist blinded to the study group, as previously described by Erboga et al. [40].

2.12. Ultrastructural Studies. The heart and kidney tissues were selected for ultrastructural studies. The tissues were trimmed to $2-4 \mathrm{~mm}$ slice and fixed in $2.5 \%$ glutaraldehyde containing $0.2 \mathrm{M}$ sodium cacodylate buffer ( $\mathrm{pH}$ 7.2) for 12 hours at $4^{\circ} \mathrm{C}$ and were further processed in accordance with the rib method described by Bakar et al. [41]. The embedded block was trimmed to form a trapezoidal shape. An ultrathin section (50-70 nm thick) was cut using a diamond knife, which was mounted on a copper grid and then stained with uranyl acetate and lead citrate. The tissues were viewed and examined under the high-resolution transmission electron microscope (HRTEM, JEOL, JEM2100F, USA) at $80 \mathrm{kV}$ with the operator blinded to the group, and 5 to 8 micrographs were taken randomly.

2.13. Statistical Analysis. All the data were analysed using GraphPad Prism version 7 (Prism GraphPad Software, Inc., USA). Descriptive statistics and graphs were used for the clinical signs and observations. However, sample size in all the groups is equal, the results were expressed as mean and standard deviation, and one-way ANOVA (analysis of variance) with Turkey's multiple range test method was used for multiple comparisons for haematological parameters and serum biochemical value while Kruskal-Wallis test was used for cardiac biomarker and histological tissue scoring, with a $p$ value $<0.05$ considered statistically significant in all the analysis.

\section{Results}

3.1. Physical and Clinical Observation and Mortality. No mortality and evidence of cardiotoxicity were observed in all the dogs within the study period. However, anorexia, soft watery faeces, and dermal lesions, which were expressed as alopecia with pruritus on the facial region, were observed after the 4th cycle (cumulative dose of $120 \mathrm{mg} / \mathrm{m}^{2}$ ) of free DOX in all 2 out of 3 dogs as a predetermined toxicity sign as shown in Figure 1(a).
3.1.1. Effect of Free DOX and CS-CaCO ${ }_{3} \mathrm{NP}-\mathrm{DOX}$ at Different Cumulative Doses on Body Weight. A decrease in body weight of dogs given $30 \mathrm{mg} / \mathrm{m}^{2}$ free DOX was observed immediately after the 2 nd dose with about $9 \%$ of the body weight lost after a cumulative dose of $150 \mathrm{mg} / \mathrm{m}^{2}$. Similarly, a decrease in body weight $(8.3 \%)$ was also observed in dogs given CS-CaCO ${ }_{3} \mathrm{NP}-\mathrm{DOX}\left(50 \mathrm{mg} / \mathrm{m}^{2}\right)$ at a cumulative dose of $200 \mathrm{mg} / \mathrm{m}^{2}$ as compared to the initial body weight.

However, an increase in body weight was observed in dogs given CS-CaCO ${ }_{3} \mathrm{NP}-\mathrm{DOX}$ at $30 \mathrm{mg} / \mathrm{m}^{2}$ and $20 \mathrm{mg} / \mathrm{m}^{2} 3$ weeks after the second dose as shown in Figure 1(b). The decrease in body weight observed in dogs given a cumulative dose of free DOX $\left(150 \mathrm{mg} / \mathrm{m}^{2}\right)$ and cumulative dose of CS$\mathrm{CaCO}_{3} \mathrm{NP}-\mathrm{DOX}\left(250 \mathrm{mg} / \mathrm{m}^{2}\right)$ was significant as compared to those given normal saline $(p=0.02$ and $p=0.014)$, respectively, within the last 3 weeks of the study. However, the increase in body weight observed was also significant in dogs given cumulative dose of $\mathrm{CS}-\mathrm{CaCO}_{3} \mathrm{NP}-\mathrm{DOX}\left(100 \mathrm{mg} / \mathrm{m}^{2}\right)$ and below when compared to those given free DOX $(p=0.008)$ within the last 6 weeks of the experiment.

\subsubsection{Effect of Free DOX and CS-CaCO ${ }_{3} \mathrm{NP}-\mathrm{DOX}$ at Different} Cumulative Doses on Rectal Temperature. A slight increase in the rectal temperature ranging from 0.5 to $1^{\circ} \mathrm{C}$ was observed in all the dogs within 12 hours after administration. However, the increase in the rectal temperature upon administration of cumulative dose of free DOX $120 \mathrm{mg} / \mathrm{m}^{2}$ as compared to that of normal saline and cumulative dose of $\mathrm{CS}-\mathrm{CaCO}_{3} \mathrm{NP}-\mathrm{DOX}$ (dose range between 120 and $150 \mathrm{mg} / \mathrm{m}^{2}$ ) was statistically significant with $p \leq 0.0001$, $p \leq 0.0001$, and $p=0.027$, respectively, after the $3 \mathrm{drug}$ administrations (Figure 1(c)).

3.1.3. Effects of Free DOX and CS-CaCO${ }_{3} \mathrm{NP}-\mathrm{DOX}$ at Different Cumulative Doses on Heart Rate. No significant change in the heart rates was observed throughout the 15 weeks of the free DOX and CS- $\mathrm{CaCO}_{3} \mathrm{NP}-\mathrm{DOX}$ administration at different doses, with normal heart sound originating from the sinus node except for the dogs given free DOX at a cumulative dose of above $120 \mathrm{mg} / \mathrm{m}^{2}$ that exhibited shallow heart sound. There was also a significant decrease in the heart rate in the dogs given cumulative dose of above $90 \mathrm{mg} / \mathrm{m}^{2}$ as compared to the dogs given normal saline $(p=0.017)$ as shown in Figure $1(d)$.

3.2. Urinalysis. No significant changes in the urine samples of the dogs given $\mathrm{CS}-\mathrm{CaCO}_{3} \mathrm{NP}-\mathrm{DOX}$ at different doses were observed as compared to those given normal saline (Figure $1(\mathrm{e}))$. However, slight change in urine colour was observed from transparent-yellowish colour to amber colour 8 hours after the 3rd cycle of free DOX administration.

3.3. Thoracic Radiological Findings and Mean Vertebral Heart Size. The right lateral radiographic image of the dogs given free DOX $30 \mathrm{mg} / \mathrm{m}^{2}$ at a cumulative dose of $150 \mathrm{mg} / \mathrm{m}^{2}$ revealed a large cardiac silhouette on the ventricular border with cranial bulge close to the sternum. The cardiac apex was 


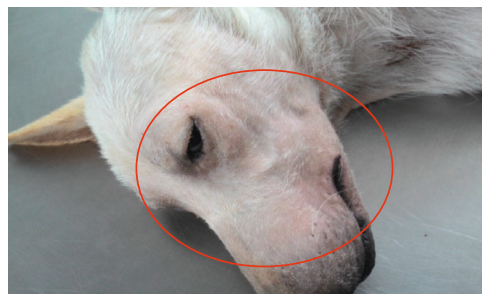

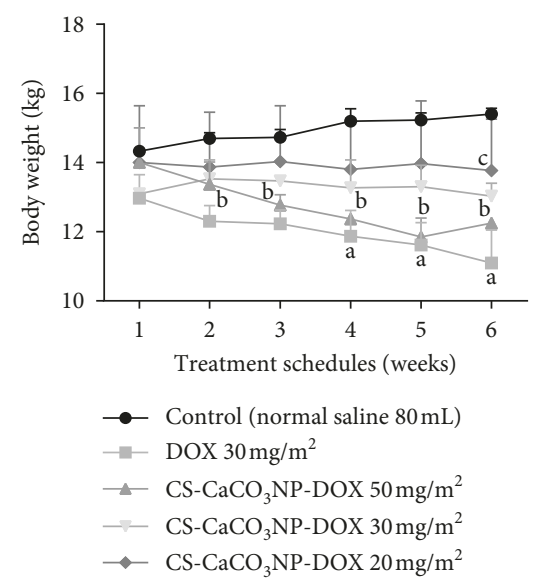

(b)

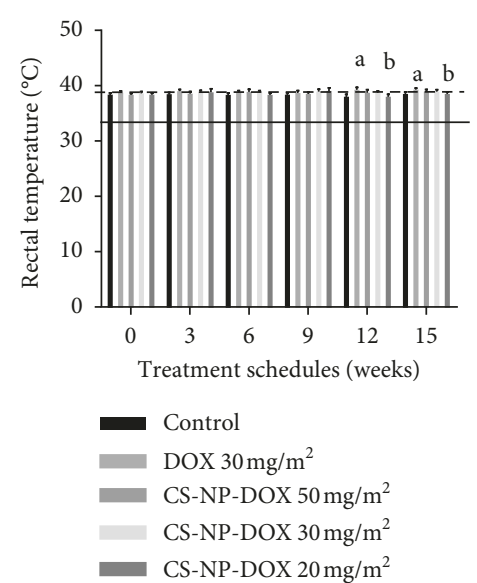

(c) (a)

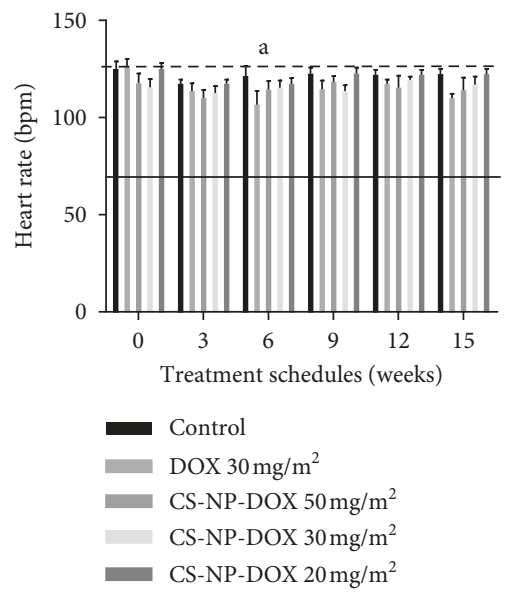

(d)

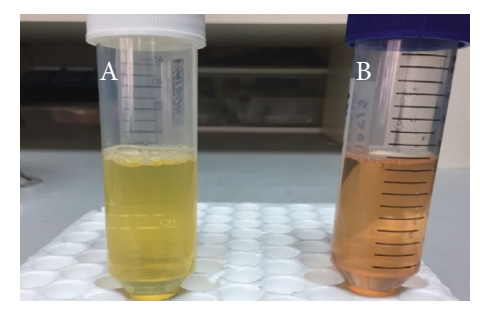

(e)

FIgURE 1: Effect on physical and clinical parameters. (a) Dermal lesion on the facial region of the dogs given free DOX after the 4th cycle. (b) Effect of treatment groups from onset to 3 weeks after the 5th cycle on the body weight $(\mathrm{kg})$. (c) Effect of treatment groups from onset to 3 weeks after the 5 th cycle on rectal temperature $\left({ }^{\circ} \mathrm{C}\right)$. (d) Effect of treatment groups from onset to 3 weeks after the 5 th cycle on heart rate (bpm). Values are expressed as mean \pm standard deviation. Different alphabets indicate statistical significance $(p<0.05)$ between groups at different cumulative doses with $\mathrm{a}, \mathrm{b}, \mathrm{c}$, and d representing significant difference with control, DOX $30 \mathrm{mg} / \mathrm{m}^{2}, \mathrm{CS}-\mathrm{CaCO} \mathrm{NP}_{3} \mathrm{DOX}$ $50 \mathrm{mg} / \mathrm{m}^{2}, \mathrm{CS}-\mathrm{CaCO}_{3} \mathrm{NP}-\mathrm{DOX} 30 \mathrm{mg} / \mathrm{m}^{2}$, and CS-CaCO${ }_{3} \mathrm{NP}-\mathrm{DOX} 20 \mathrm{mg} / \mathrm{m}^{2}$, respectively. (e) Urine colour change in dogs given free DOX and $\mathrm{CS}-\mathrm{CaCO}_{3} \mathrm{NP}-\mathrm{DOX}$ at different doses.

slightly displaced with the conus arteriosus on the dorsoventral view (Figure 2).

A mean increase in vertebral heart score (VHS) of $1.36 \pm$ $0.55 \mathrm{v}$ was observed in the dogs given free DOX at a cumulative dose of $150 \mathrm{mg} / \mathrm{m}^{2}$ as compared to the baseline VHS value. The increase in VHS was not statistically significant in the groups of dogs given $\mathrm{CS}-\mathrm{CaCO}_{3} \mathrm{NP}-\mathrm{DOX}$ at different cumulative doses as compared to the respective baseline VHS value $(p=0.0501)$. Similarly, the $p$ values for the cumulative doses in dogs given $\mathrm{CS}-\mathrm{CaCO}_{3} \mathrm{NP}-\mathrm{DOX}$ $\left(250 \mathrm{mg} / \mathrm{m}^{2}\right)$, CS-CaCO ${ }_{3} \mathrm{NP}-\mathrm{DOX}\left(150 \mathrm{mg} / \mathrm{m}^{2}\right)$, and CS$\mathrm{CaCO}_{3} \mathrm{NP}-\mathrm{DOX}\left(100 \mathrm{mg} / \mathrm{m}^{2}\right)$ are $0.2354,0.3394$, and 0.1088 , respectively, when compared to their respective baseline values (Figure 2). Free DOX and CS-CaCO ${ }_{3} \mathrm{NP}-\mathrm{DOX}$. No change was observed in the ventricular rate and PR interval in dogs when compared with the baseline values before administration of the drug (Figure 3), respectively. The ECG recorded a significant decrease in the duration of $\mathrm{P}$ wave in dogs given a cumulative dose of free DOX $150 \mathrm{mg} / \mathrm{m}^{2}$ as compared to the baseline $\mathrm{P}$ wave $(p=0.0125)$ (Figure 3$)$. In addition, the changes in the $\mathrm{P}$ wave were within the normal reference range in the dogs given $\mathrm{CS}-\mathrm{CaCO}_{3} \mathrm{NP}-\mathrm{DOX}$ and the changes in the PII amplitude were also observed, although there was an increase in the PII amplitude in the dogs given free DOX (Figure 8). However, a significant decrease in QRS duration was detected in the dogs given free DOX at a cumulative dose $\left(150 \mathrm{mg} / \mathrm{m}^{2}\right)$ as compared to the initial baseline data $(p=0.0134)$ (Figure 3 ). In addition, the ECG also reveals a significant decrease in QRS axis in the dogs given cumulative doses of free DOX $\left(150 \mathrm{mg} / \mathrm{m}^{2}\right)$ and CS-CaCO ${ }_{3} \mathrm{NP}-\mathrm{DOX}$ $\left(250 \mathrm{mg} / \mathrm{m}^{2}\right)$ with $p=0.0166$ and $p=0.0188$, respectively (Figure 3). 


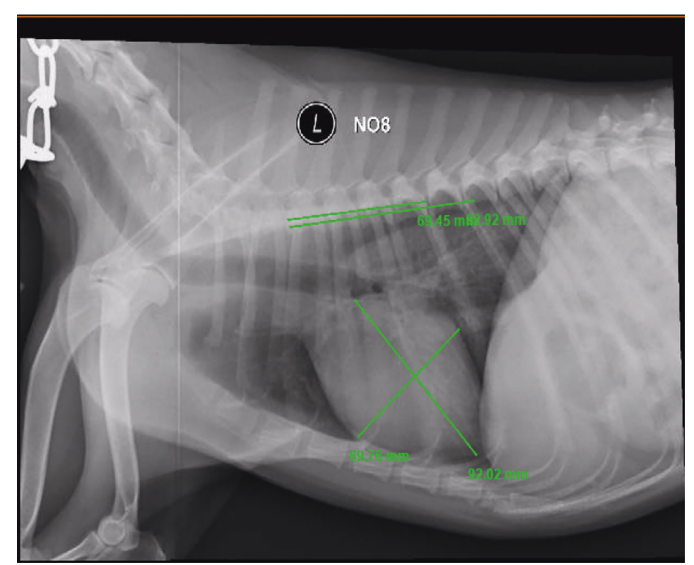

(a)

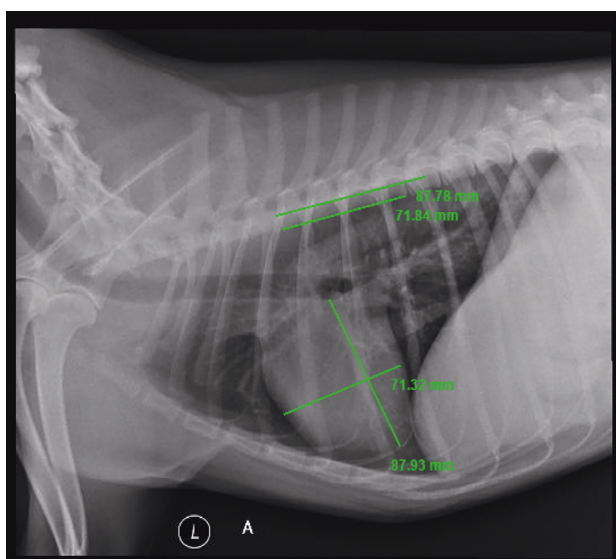

(b)

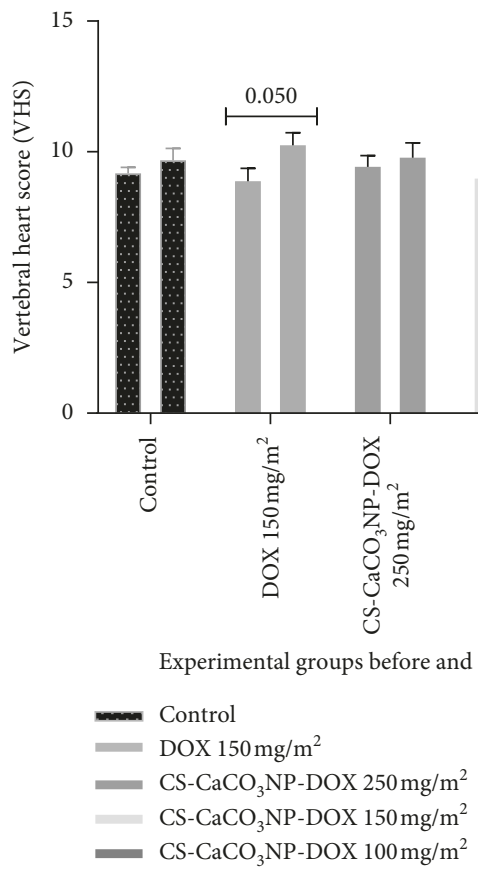

(c)

FIGURE 2: Thoracic radiographs and heart size score. (a) Initial and (b) final heart size measurement using vertebral heart score (VHS) index of dogs. (c) Mean vertebral heart score of dogs treated with free DOX and CS-CaCO ${ }_{3} \mathrm{NP}-\mathrm{DOX}$ at different cumulative doses. All the data are expressed as mean $\pm \mathrm{SD}, n=3$.

However, there is a mean significant increase in the QT interval in the dogs given free DOX 3 weeks after a cumulative dose of $150 \mathrm{mg} / \mathrm{m}^{2}(p=0.0357)$ and in those given CS$\mathrm{CaCO}_{3} \mathrm{NP}$-DOX $250 \mathrm{mg} / \mathrm{m}^{2}(p=0.0464)$ as compared to the baseline values (Figure 3 ).

\subsection{Haematology, Serum Biochemistry, and Biomarkers for Cardiac Injury}

3.5.1. Effect of Free DOX and CS-CaCO ${ }_{3} \mathrm{NP}-\mathrm{DOX}$ at Different Cumulative Doses on Haematological Profile. Haematological changes observed were dose-related specifically on the red blood cell (RBCs), platelet cells (PLTs), and white blood cells (WBCs) with significant changes at a different level when compared to the respective cell levels in the dogs given normal saline. Significant variations were observed in the dogs given cumulative dose of above $90 \mathrm{mg} / \mathrm{m}^{2}$ and CS$\mathrm{CaCO}_{3}$ NP-DOX $150 \mathrm{mg} / \mathrm{m}^{2}$ and above as compared to the cell levels in the dogs given normal saline. As seen with RBC $(p=0.0079)$, after a cumulative dose of free DOX $150 \mathrm{mg} / \mathrm{m}^{2}$, and PLT $(<0.05)$, at cumulative dose of $60 \mathrm{mg} / \mathrm{m}^{2}$, there is a mean significant decrease in the WBC at a cumulative dose of $90 \mathrm{mg} / \mathrm{m}^{2}$ as compared to the dogs given normal saline $(p=0.007)$ (Figure 4). However, no significant alteration in the cell profiles in the dogs given $\mathrm{CS}-\mathrm{CaCO}_{3} \mathrm{NP}-\mathrm{DOX}$ $\left(30 \mathrm{mg} / \mathrm{m}^{2}\right)$ at a cumulative dose of $150 \mathrm{mg} / \mathrm{m}^{2}$ and below was observed as compared to the dogs given normal saline.

3.5.2. Effect of Free DOX and CS-CaCO ${ }_{3} \mathrm{NP}-\mathrm{DOX}$ at Different Cumulative Doses on Serum Enzyme Function Level. 


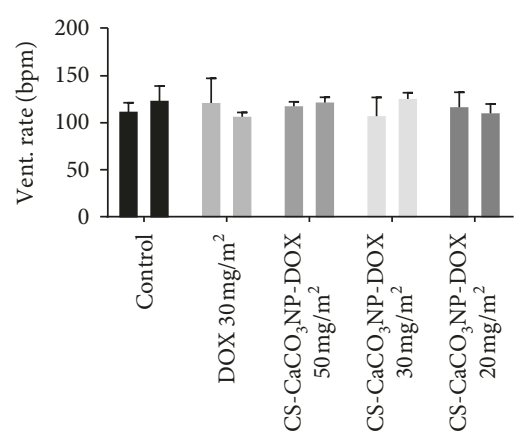

Experimental groups before and after treatment

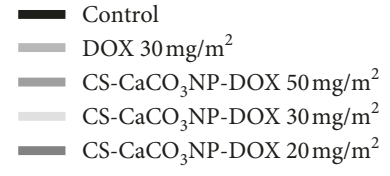

(a)

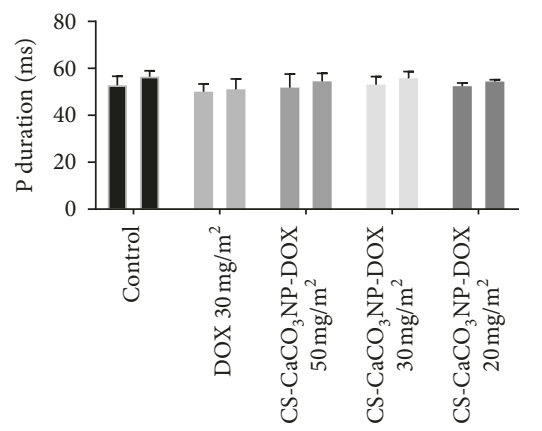

Experimental groups before and after treatment

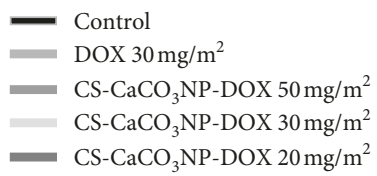

(c)

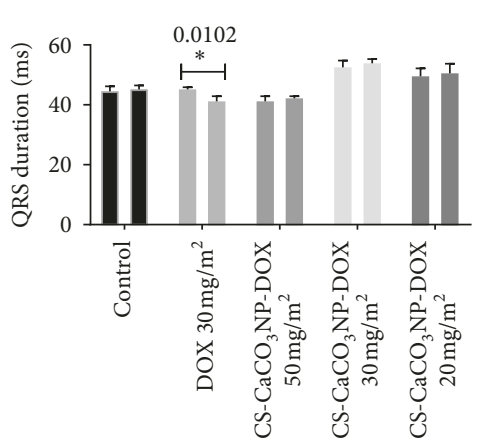

Experimental groups before and after treatment

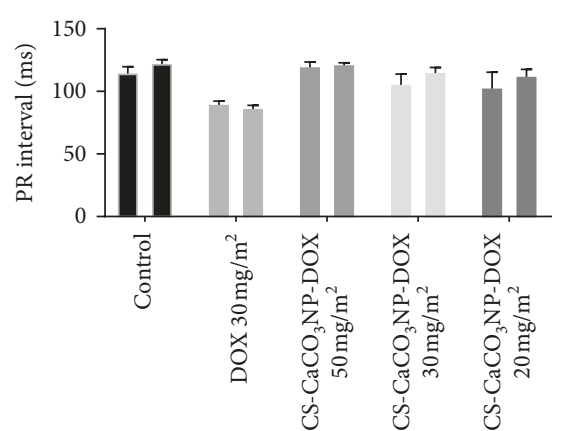

Experimental groups before and after treatment

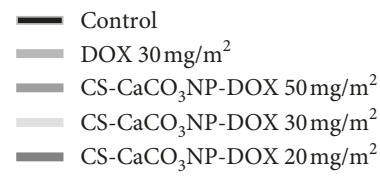

(b)

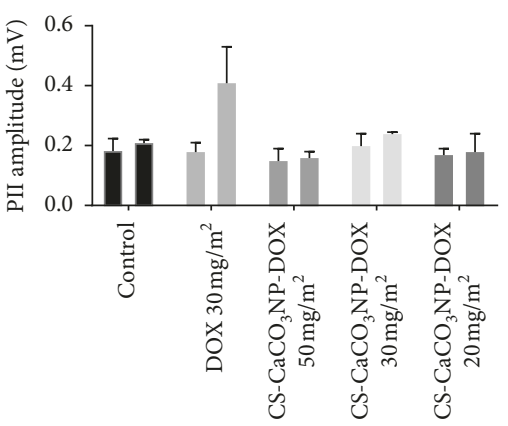

Experimental groups before and after treatment

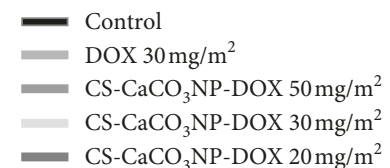

(d)

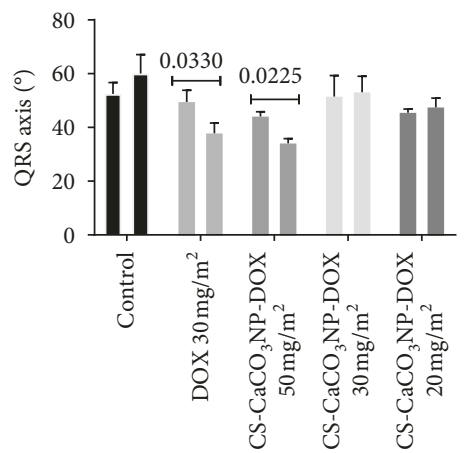

Experimental groups before and after treatment

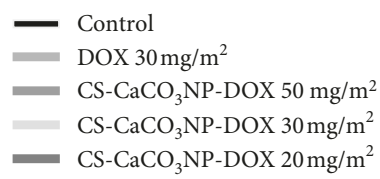

(e)

(f)

Figure 3: Continued. 


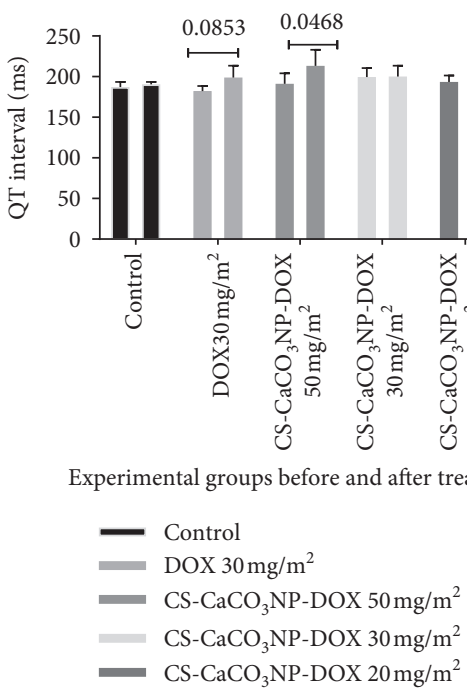

(g)

Figure 3: Electrocardiogram changes due to cumulative free DOX $150 \mathrm{mg} / \mathrm{m}^{2}$ and different CS-CaCO ${ }_{3} \mathrm{NP}$-DOX cumulative formulation regimen ranging from 100 to $250 \mathrm{mg} / \mathrm{m}^{2}$. (a) Ventricular rate, (b) PR interval, (c) P wave, (d) PII amplitude, (e) QRS duration, (f) QRS axis, and (g) QT interval. Values are expressed as mean \pm standard deviation. $p<0.05$ is considered significant.

The liver, renal, and structural membrane injury biomarkers were monitored, with no significant increase in the mean ALP value in the dogs given CS-CaCO 3 NP-DOX $150 \mathrm{mg} / \mathrm{m}^{2}$ and below as compared to the baseline value and to the mean serum level in those given normal saline $(p=0.9964$ and $p=0.9914$ ) (Figure 4). However, a significant change in the mean level was observed in the dogs given free DOX at a cumulative dose of $120 \mathrm{mg} / \mathrm{m}^{2}$ and CS-CaCO ${ }_{3} \mathrm{NP}-\mathrm{DOX}$ at dose above $150 \mathrm{mg} / \mathrm{m}^{2}$ when compared to the baseline value and mean levels in those given normal saline $p \leq 0.0001$ and $p=0.0003$, respectively (Figure 4). In addition, similar pattern of mean serum elevation in AST was observed with $p \leq 0.0001$ and $p \leq 0.0001$ in dogs given free DOX $90 \mathrm{mg} / \mathrm{m}^{2}$ and $\mathrm{CS}-\mathrm{CaCO}_{3} \mathrm{NP}-\mathrm{DOX}$ at cumulative dose of above $200 \mathrm{mg} / \mathrm{m}^{2}$, respectively (Figure 4), whereas the mean ALT level was significantly higher with free DOX and CS$\mathrm{CaCO}_{3} \mathrm{NP}-\mathrm{DOX}$ at cumulative dose of above $150 \mathrm{mg} / \mathrm{m}^{2}$ when compared to the mean level in the dogs given normal saline $p=0.0052$ and 0.0285 , respectively (Figure 4); however, LDH, CK, Crea, and BUN all show similar pattern of the elevation in the enzyme level as compared to the baseline mean value and the corresponding levels in the dogs given normal saline (Figure 4).

3.5.3. Quantification of Serum Canine Cardiac Troponin I $(c T n-I)$. The serum cardiac troponin cTn-I concentration of the dogs over the period of the study is shown in Figure 5. The serum cTn-I was significantly higher in the dogs given free DOX $\left(30 \mathrm{mg} / \mathrm{m}^{2}\right)$, after cumulative dose $\left(90 \mathrm{mg} / \mathrm{m}^{2}\right)$ $(p=0.0003)$, and at the end of the experiment 15 weeks cumulative dose of $150 \mathrm{mg} / \mathrm{m}^{2}(p=0.0045)$ as compared to serum cTn-I of the control dogs. There was also an increase in the serum biomarker in dogs given $\mathrm{CS}-\mathrm{CaCO}_{3} \mathrm{NP}-\mathrm{DOX}$ $50 \mathrm{mg} / \mathrm{m}^{2}\left(150 \mathrm{mg} / \mathrm{m}^{2}\right)(p=0.0083)$ and at cumulative dose of $250 \mathrm{mg} / \mathrm{m}^{2}(p=0.0091)$ as compared to those in the control group. In addition, the mean levels of serum cardiac troponin in dogs given free DOX at a cumulative dose of above $90 \mathrm{mg} / \mathrm{m}^{2}$ were significantly higher as compared to those given cumulative doses of the CS-CaCO $\mathrm{CO}_{3} \mathrm{NP}-\mathrm{DOX}$ $150 \mathrm{mg} / \mathrm{m}^{2}$ and below (Figure 5).

3.5.4. Quantification of Serum NT-Protein Brain Natriuretic Peptides (proBNP). A significant increase in the proBNP was recorded after a cumulative dose of $60 \mathrm{mg} / \mathrm{m}^{2}$ in dogs given free DOX $30 \mathrm{mg} / \mathrm{m}^{2}$ as compared to the level of proBNP in the dogs in the control group $(p=0.0042)$. In addition, a significant elevation in NT-proBNP in the dogs given a cumulative dose of CS-CaCO ${ }_{3} \mathrm{NP}-\mathrm{DOX} 50 \mathrm{mg} / \mathrm{m}^{2}$ $\left(200 \mathrm{mg} / \mathrm{m}^{2}\right)$ was observed when compared to the mean concentration to the corresponding level of the control group. However, NT-proBNP in the serum at a cumulative dose of CS-CaCO ${ }_{3} \mathrm{NP}-\mathrm{DOX} 50 \mathrm{mg} / \mathrm{m}^{2}\left(80 \mathrm{mg} / \mathrm{m}^{2}\right.$ and above) significantly differs from the mean level of the NTproBNP in dogs given a cumulative dose of $60 \mathrm{mg} / \mathrm{m}^{2}$ of the free DOX (Figure 5).

3.6. Gross Anatomical Alternations at Necropsy. Grossly, mild pinpoint haemorrhage was observed on the left ventricular wall of the heart in 2 out of 3 dogs given cumulative dose of free DOX $150 \mathrm{mg} / \mathrm{m}^{2}$ with swallowed edges of the liver and the right lobe appeared rounded in all 3 dogs as compared to the liver of the control of dogs given normal saline. However, the kidney appeared normal with no gross lesions. In contrast, the heart and kidneys of the dogs given different doses of CS-CaCO $\mathrm{CP}_{3} \mathrm{NP}-\mathrm{DOX}$ and normal saline did not show any gross pathological lesions as shown in Figure 6.

3.6.1. Morphometry of the Body Weight, Heart Weight, and Ventricular Mass Measurement. The heart weight-to-body 

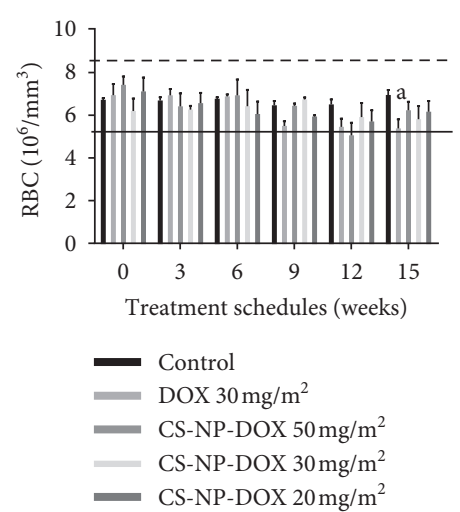

(a)
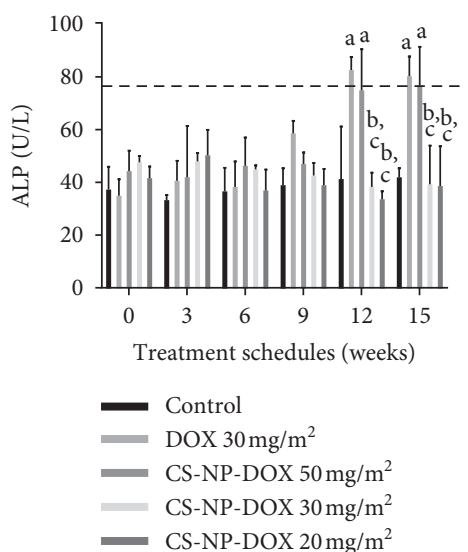

(d)
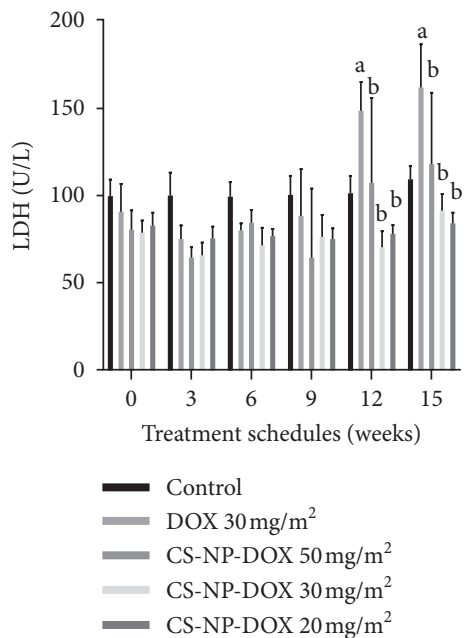

(g)
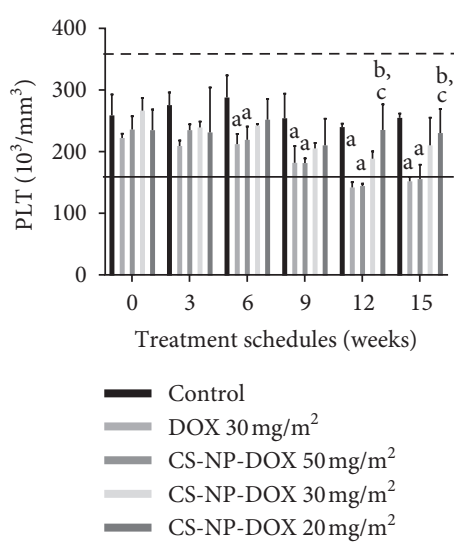

(b)
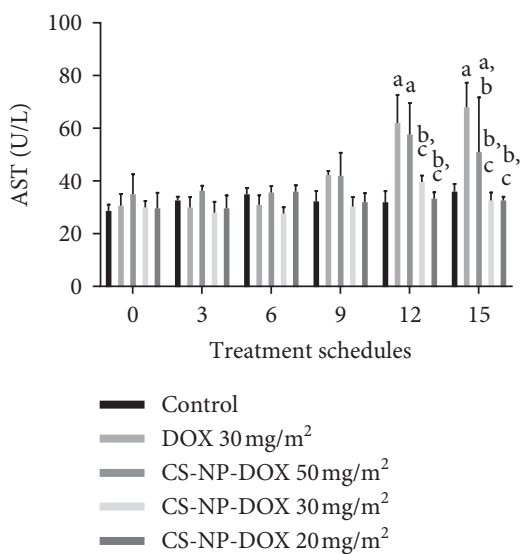

(e)
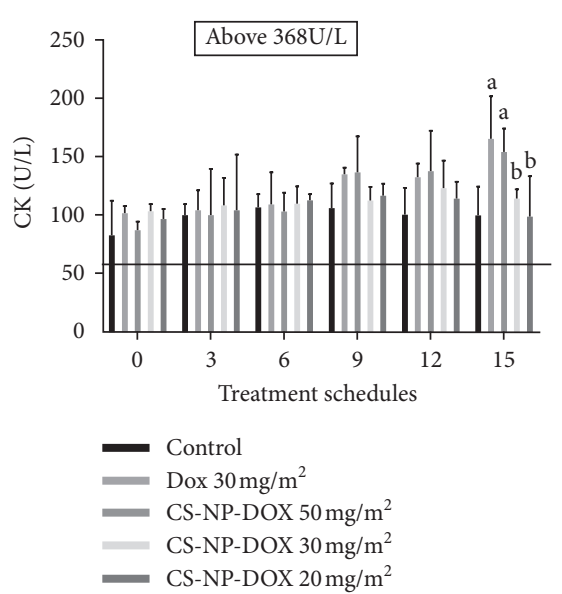

(h)

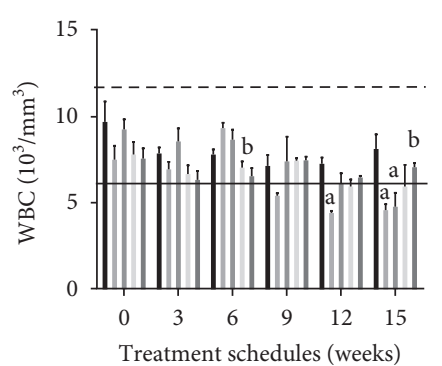

Control

DOX $30 \mathrm{mg} / \mathrm{m}^{2}$

CS-NP-DOX $50 \mathrm{mg} / \mathrm{m}^{2}$

CS-NP-DOX $30 \mathrm{mg} / \mathrm{m}^{2}$ CS-NP-DOX $20 \mathrm{mg} / \mathrm{m}^{2}$

(c)
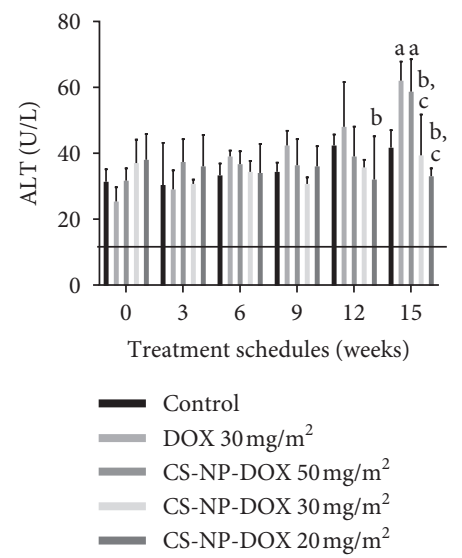

(f)

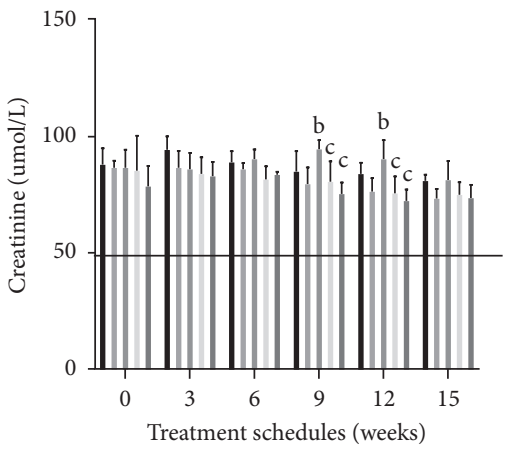

Control

DOX $30 \mathrm{mg} / \mathrm{m}^{2}$

CS-NP-DOX $50 \mathrm{mg} / \mathrm{m}^{2}$ CS-NP-DOX $30 \mathrm{mg} / \mathrm{m}^{2}$ CS-NP-DOX $20 \mathrm{mg} / \mathrm{m}^{2}$

(i)

Figure 4: Continued. 


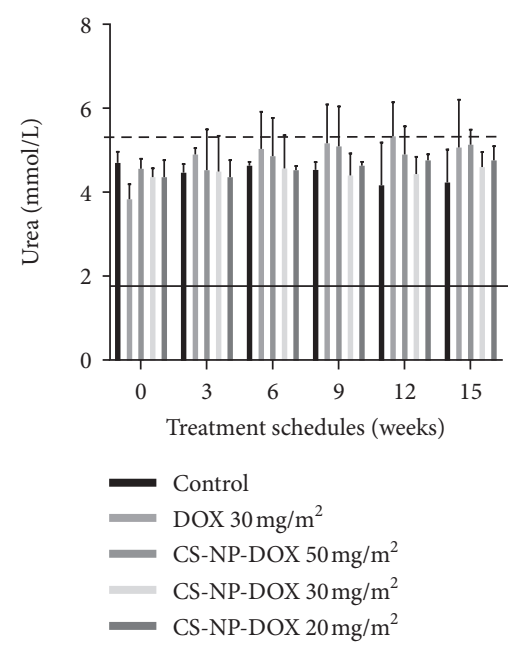

(j)

Figure 4: Effect of treatment groups from onset to 3 weeks after the 5th cycle on the haematological profile and serum biochemistry. (a) Red blood cells (RBCs) $\left(10^{6} / \mathrm{mm}^{3}\right)$, (b) platelet cells (PLT) $\left(10^{3} / \mathrm{mm}^{3}\right)$, (c) white blood cells (WBC) $\left(10^{3} / \mathrm{mm}^{3}\right)$, (d) alkaline phosphatase (ALP) ( $\left.\mu / \mathrm{L}\right)$, (e) aspartate aminotransferase (AST) $(\mu / \mathrm{L}),(\mathrm{f})$ alanine aminotransferase (ALT) $(\mu / \mathrm{L}),(\mathrm{g})$ lactate dehydrogenase $(\mathrm{LDH})(\mu / \mathrm{L}),(\mathrm{h}) \mathrm{creatinine}$ kinase $(\mathrm{CK})(\mu / \mathrm{L})$, (i) creatinine (Crea) $(\mu \mathrm{mol} / \mathrm{L})$, and $(\mathrm{j})$ urea $(\mathrm{mmol} / \mathrm{L})$. Values are expressed as mean \pm standard deviation. Different alphabets indicate statistical significance $(p<0.05)$ between groups at different cumulative doses with a, b, $c$, and d representing significant difference with control, DOX $30 \mathrm{mg} / \mathrm{m}^{2}$, CS-CaCO ${ }_{3}$ NP-DOX $50 \mathrm{mg} / \mathrm{m}^{2}$, CS-CaCO 3 NP-DOX $30 \mathrm{mg} / \mathrm{m}^{2}$, and CS-CaCO ${ }_{3} \mathrm{NP}-\mathrm{DOX} 20 \mathrm{mg} / \mathrm{m}^{2}$, respectively.

weight ratio increased significantly in dogs given free DOX at a cumulative dose of $150 \mathrm{mg} / \mathrm{m}^{2}$ as compared to those given normal saline $(p=0.0020)$, whereas the dogs given different doses of $\mathrm{CS}-\mathrm{CaCO}_{3} \mathrm{NP}-\mathrm{DOX}$ did not show any significant change as compared to those dogs given normal saline (Figure 7). There was a significant decrease in the left ventricular wall thickness in the dogs given free DOX at a cumulative dose of $150 \mathrm{mg} / \mathrm{m}^{2}$ as compared to those given CS-CaCO ${ }_{3} \mathrm{NP}-\mathrm{DOX}$ at a cumulative dose of $250 \mathrm{mg} / \mathrm{m}^{2}(p=0.00341)$. However, neither increase nor decrease was observed in the right ventricular thickness of all the dogs (Figure 7).

3.7. Histopathological Alteration on the Cardiac and Kidney Tissues due to Cumulative Doses of DOX and $\mathrm{CS}-\mathrm{CaCO}{ }_{3} \mathrm{NP}$ $D O X$. The microscopic investigation revealed that no pathological lesions were observed on the myocardium and kidney tissues of dogs given normal saline, which was similar to those given $\mathrm{CS}-\mathrm{CaCO}_{3} \mathrm{NP}-\mathrm{DOX}$ at a cumulative dose of $150 \mathrm{mg} / \mathrm{m}^{2}$ and below. However, the significant changes were observed in the tissues of dogs given free DOX at a cumulative dose of $150 \mathrm{mg} / \mathrm{m}^{2}$ and dogs given a cumulative dose of CS-CaCO${ }_{3} \mathrm{NP}-\mathrm{DOX}$ above $150 \mathrm{mg} / \mathrm{m}^{2}$.

The histological sections of ventricular myocardium and kidney tissues of the dogs given normal saline and CS$\mathrm{CaCO}_{3} \mathrm{NP}-\mathrm{DOX}$ at a cumulative dose of $150 \mathrm{mg} / \mathrm{m}^{2}$ appeared normal as shown in Figure 8. The histological sections of the left ventricle of dogs given cumulative doses of $150 \mathrm{mg} / \mathrm{m}^{2}$ of free DOX showed multiple areas of myocardial intercellular vacuolation of different sizes which disrupts the myofilaments with clusters of inflammatory infiltration cells predominantly lymphocytes (Figure 8).

In addition, focal myocytolysis was also seen in some areas which appeared as myofibril derangement of myocardial fibres associated with halo vacuoles, which are area of depleted glycogen and thus replaced by collagen as compared to the histological section of left ventricular myocardial of the dogs given normal saline which retained its myocardial architecture morphology with clearly distinct dense central nucleus (Figure 8). Furthermore, there was no myocyte disruption in dog's ventricle and the appearance of cytoplasmic bridges at the end of myofilaments in dogs given either $\mathrm{CS}-\mathrm{CaCO}_{3} \mathrm{NP}-\mathrm{DOX}$ at a cumulative dose of $150 \mathrm{mg} / \mathrm{m}^{2}$ or with less concentration as shown in Figure 8.

The focal haemorrhagic area was observed in the intercellular region of myofibril in the dogs given free DOX and higher cumulative dose of CS-CaCO${ }_{3} \mathrm{NP}-\mathrm{DOX}$ above $150 \mathrm{mg} / \mathrm{m}^{2}$ (Figure 8). The myocardium of the left and right ventricles was morphologically normal with spindle-shaped central nucleus without inflammatory cell infiltration in dogs given normal saline and in dogs given $\mathrm{CS}-\mathrm{CaCO}_{3} \mathrm{NP}-$ DOX at a cumulative dose of $150 \mathrm{mg} / \mathrm{m}^{2}$ or less (Figure 8).

In the kidney, focal necrosis was observed in the renal parenchyma leading to distortion of the parenchymatous region with high number of basophilic tubular cells and dark pinpoint fragmentation of the renal tubular epithelial nuclei, few areas of haemorrhages, and slight dilation of few renal proximal tubules of the dogs given cumulative of free DOX $150 \mathrm{mg} / \mathrm{m}^{2}$ (Figure 8). In addition, decrease in the renal glomerular cellularity associated with atrophied glomerulus resulting in widening of Bowman's capsular space was observed in the dogs given cumulative dose of free DOX $150 \mathrm{mg} / \mathrm{m}^{2}$ as compared to the control group, which shows normal morphological appearance of the renal corpuscle with tuft glomeruli and Bowman's capsule space and narrowed luminal proximal convoluted tubules lined with cuboidal cells as shown in Figure 8. However, a similar focal necrotic area with renal tubular nuclear fragmentation and 


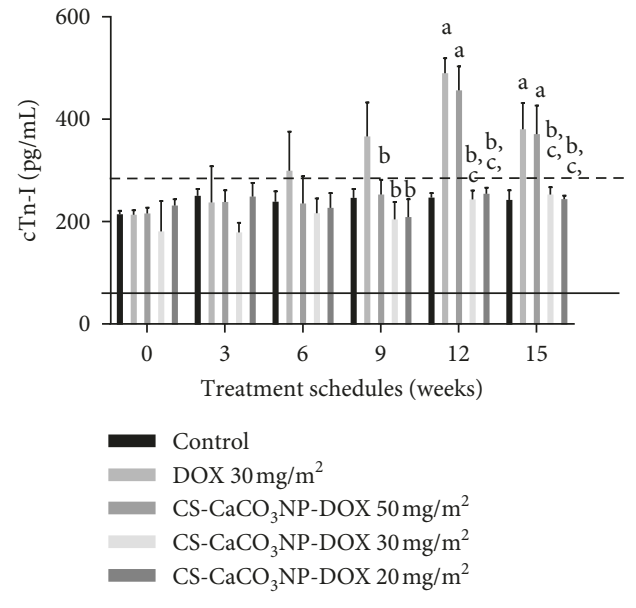

(a)

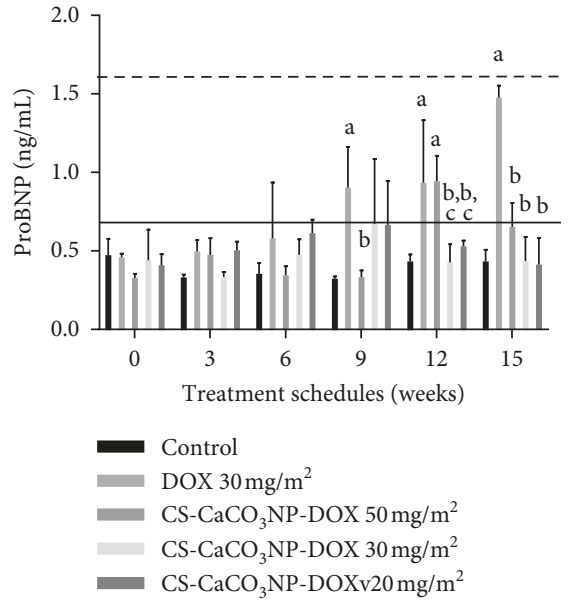

(b)

Figure 5: Cardiac injury biomarker. (a) Mean cardiac troponin I (cTn-I) concentration (pg/ml). (b) Mean N-terminal pro-brain natriuretic peptide (proBNP) concentration $(\mathrm{ng} / \mathrm{ml})$ of treatment groups from onset to 3 weeks after the 5 th dose. Values are expressed as mean \pm standard deviation. Different alphabets indicate statistical significance $(p<0.05)$ between groups at different cumulative doses with a, b, $\mathrm{c}$, and $d$ representing significant difference with control, DOX $30 \mathrm{mg} / \mathrm{m}^{2}$, CS-CaCO ${ }_{3} \mathrm{NP}-\mathrm{DOX} 50 \mathrm{mg} / \mathrm{m}^{2}, \mathrm{CS}-\mathrm{CaCO}{ }_{3} \mathrm{NP}-\mathrm{DOX} 30 \mathrm{mg} / \mathrm{m}^{2}$, and CS-CaCO 3 NP-DOX $20 \mathrm{mg} / \mathrm{m}^{2}$, respectively.
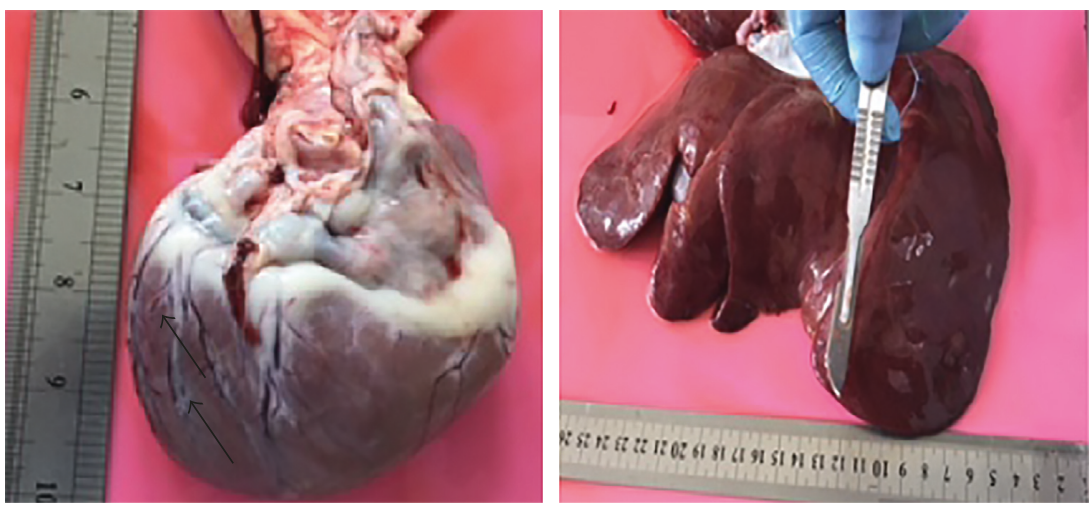

FIGURE 6: Gross pathological lesions on the heart and liver of dogs given cumulative dose of free DOX $150 \mathrm{mg} / \mathrm{m}^{2}$.

disrupted epithelium was observed in the dogs given CS$\mathrm{CaCO}_{3} \mathrm{NP}-\mathrm{DOX}$ at a cumulative dose of $250 \mathrm{mg} / \mathrm{m}^{2}$ as compared to the control group (Figure 8). No alteration was observed in the tubular, glomerular, and parenchymatous region in the kidney of dogs given $\mathrm{CS}-\mathrm{CaCO}_{3} \mathrm{NP}-\mathrm{DOX}$ at a cumulative dose of $150 \mathrm{mg} / \mathrm{m}^{2}$ and below (Figure 8), respectively.

A significant difference $(p<0.001)$ was observed in the intercellular vacuolation of the left ventricles between the groups $\left(\chi^{2}=(4,180)=26.211\right)$. In addition, significant difference was observed in the histological structures of ventricular myocardium in dogs given free DOX at cumulative dose of $150 \mathrm{mg} / \mathrm{m}^{2}$ and those given CS-CaCO ${ }_{3} \mathrm{NP}-\mathrm{DOX}$ at cumulative doses of $250 \mathrm{mg} / \mathrm{m}^{2}, 150 \mathrm{mg} / \mathrm{m}^{2}$, and $100 \mathrm{mg} / \mathrm{m}^{2}$ with $p<$ $0.001, r=0.198 ; p<0.001, \quad r=0.05 ; \quad p=0.154, \quad r=$ 0.02 ; and $p=0.154, r=0.02$, respectively, as compared to the control group (Figure 9).

The vacuolation in the ventricular wall observed in the experiment groups was directly related to the significant loss in myofibril $\left(\chi^{2}=(4,180)=40.138, p<0.001\right)$.
The vacuolation in the ventricular wall was significantly more in dogs given free DOX at cumulative dose of $150 \mathrm{mg} / \mathrm{m}^{2}$ and those given CS-CaCO${ }_{3} \mathrm{NP}-\mathrm{DOX}$ at $\mathrm{cu}-$ mulative doses of $250 \mathrm{mg} / \mathrm{m}^{2}$ with $p<0.001, r=0.259$ and $p<0.001, r=0.238$, respectively, as compared to those in the control group, while there was no significant difference in dogs given CS- $\mathrm{CaCO}_{3} \mathrm{NP}-\mathrm{DOX}$ at cumulative dose of $150 \mathrm{mg} / \mathrm{m}^{2}$ or lower $(p=0.079, r=0.043)$ and ( $p=1.000, r=0.014)$ when compared to those in the control group (Figure 9).

The significant difference in the cytoplasmic interstitial cellular infiltration and haemorrhages was observed among the groups $\left(\chi^{2}=(4,180)=13.068, p=0.011\right.$ and $\chi^{2}=(4,180)=$ $18.166, p=0.001)$, respectively, which were significantly higher in dogs given free DOX at cumulative dose of $150 \mathrm{mg} / \mathrm{m}^{2}$ and those given $\mathrm{CS}-\mathrm{CaCO}_{3} \mathrm{NP}-\mathrm{DOX}$ at cumulative doses of $250 \mathrm{mg} / \mathrm{m}^{2}, 150 \mathrm{mg} / \mathrm{m}^{2}$, and $100 \mathrm{mg} / \mathrm{m}^{2}$ with $(p=$ $0.003, r=0.124),(p=0.006, r=0.107),(p=0.154, \quad r=$ $0.028)$, and ( $p=0.079, r=0.043)$, respectively, as compared to those given normal saline (Figure 9). 


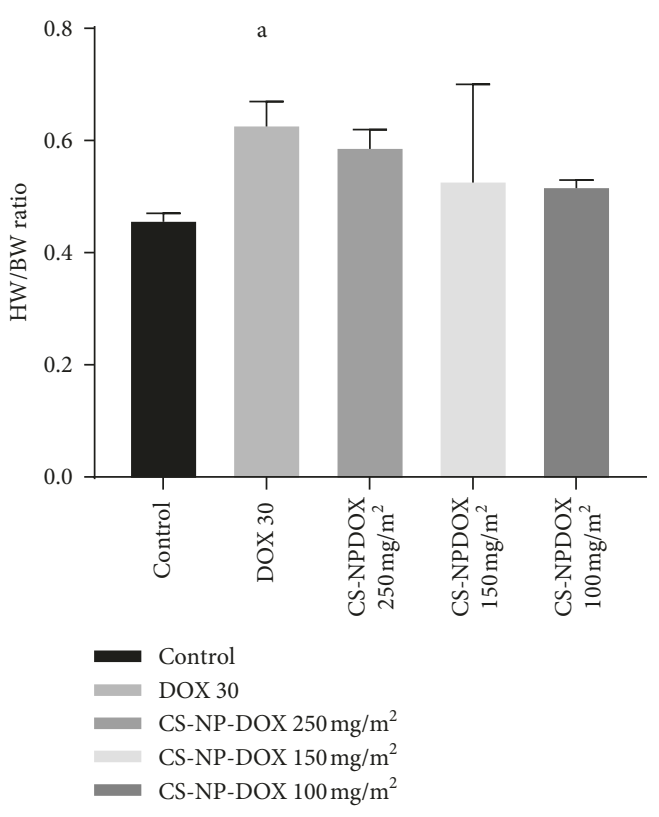

(a)
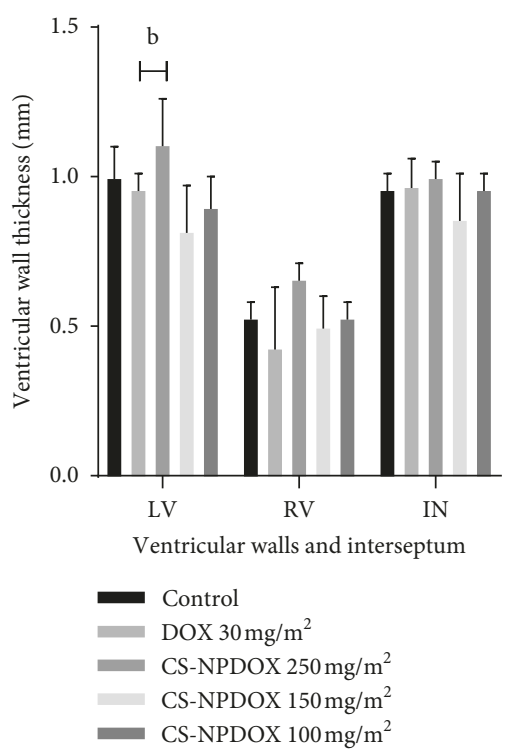

(b)

Figure 7: Morphometric assessment of the heart. (a) Mean heart weight-to-body weight ratio. (b) Mean ventricular wall thickness (mm) of dogs given normal saline, cumulative dose of free doxorubicin $150 \mathrm{mg} / \mathrm{m}^{2}, \mathrm{CS}-\mathrm{CaCO}_{3} \mathrm{NP}-\mathrm{DOX} 250 \mathrm{mg} / \mathrm{m}^{2}, \mathrm{CS}-\mathrm{CaCO} \mathrm{NP}_{3} \mathrm{DOX}$ $150 \mathrm{mg} / \mathrm{m}^{2}$, and CS-CaCO $3 \mathrm{NP}-\mathrm{DOX} 100 \mathrm{mg} / \mathrm{m}^{2}(n=3) . p<0.05$ is considered statistically significant between the groups.
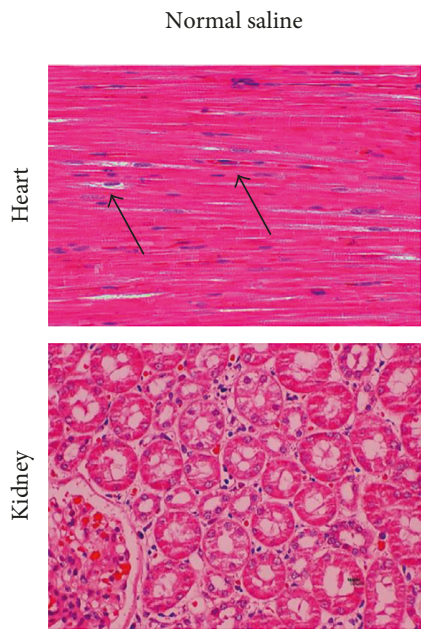

(a)
Free DOX $30 \mathrm{mg} / \mathrm{m}^{2}$
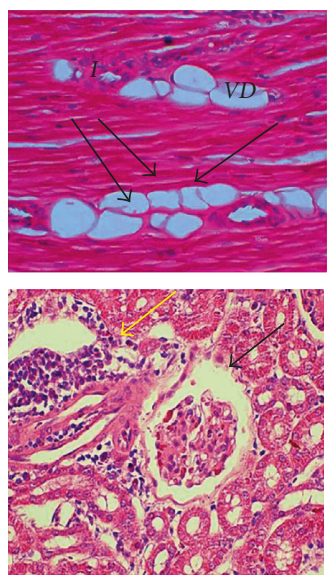

(b)
CS- $\mathrm{CaCO}_{3} \mathrm{NP}-\mathrm{DOX}$ $50 \mathrm{mg} / \mathrm{m}^{2}$
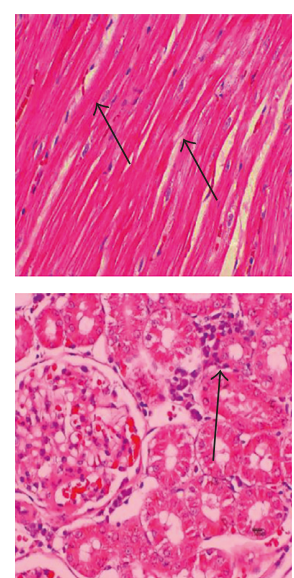

(c)
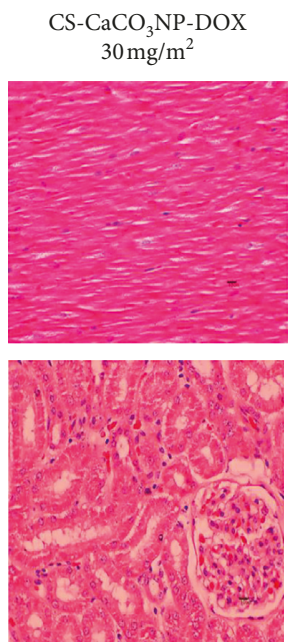

(d)

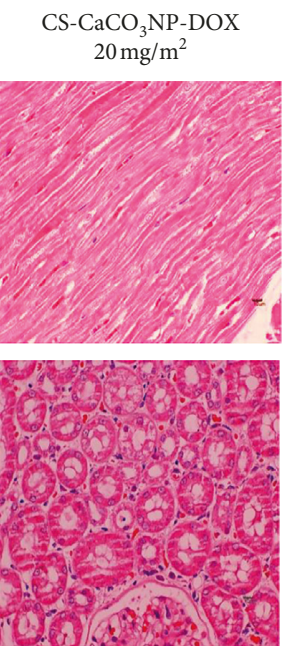

(e)

FIGURe 8: Photomicrograph of the longitudinal section of left ventricular myocardium and kidney section. (a) Ventricular myocardium and kidney section of the dogs given normal saline showing normal morphological architecture of the cardiomyocytes, myocardial fibres, and both glomerular (G) and renal tubular structure (PT). (b) Myocardium of the dogs given free DOX $150 \mathrm{mg} / \mathrm{m}^{2}$ showing myofibrillar loss, myocardial fibre disruption, multifocal cytoplasmic vacuolation (V), cardiomyocyte disorientation, cellular infiltration (I), and myocytolysis (M) with the kidney section showing dilated glomerular capsular space and dilation of the proximal renal tubular (DPT) with severe intercellular infiltration. (c) Myocardium of the dogs given CS-CaCO $\mathrm{CNP}_{3} \mathrm{NOX} 250 \mathrm{mg} / \mathrm{m}^{2}$ showing myofibrillar loss, vacuolation (v), cardiomyocyte disorientation, and cellular infiltration with the kidney section showing dilated renal tubules and focal areas of congestion. (d) Myocardium of the dogs given CS-CaCO${ }_{3} \mathrm{NP}-\mathrm{DOX} 150 \mathrm{mg} / \mathrm{m}^{2}$ showing normal myofibril with spindle-shaped centrally placed cardiomyocytes with the kidney section revealing normal architecture glomerulus and renal tubules. (e) Myocardium and kidney section of the dogs given $\mathrm{CS}-\mathrm{CaCO}_{3} \mathrm{NP}-\mathrm{DOX} 100 \mathrm{mg} / \mathrm{m}^{2}$ showing normal myofibril structure and normal structural morphology of glomerulus and renal tubules ( $\mathrm{H} \& \mathrm{E})$ Scale bar $10 \mu \mathrm{m}$. 


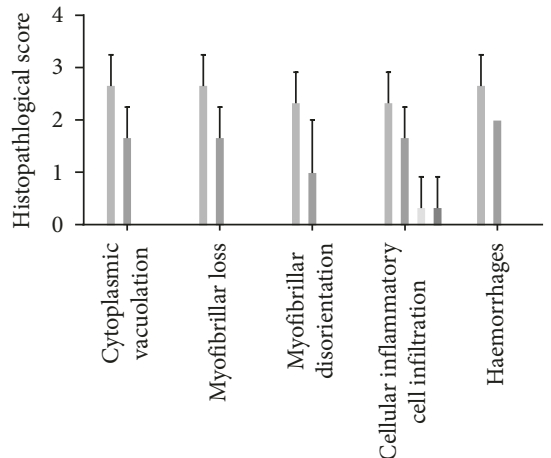

Histopathological changes on the heart tissue

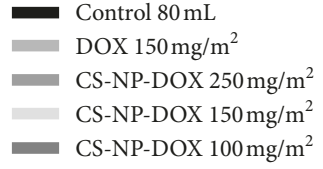

(a)

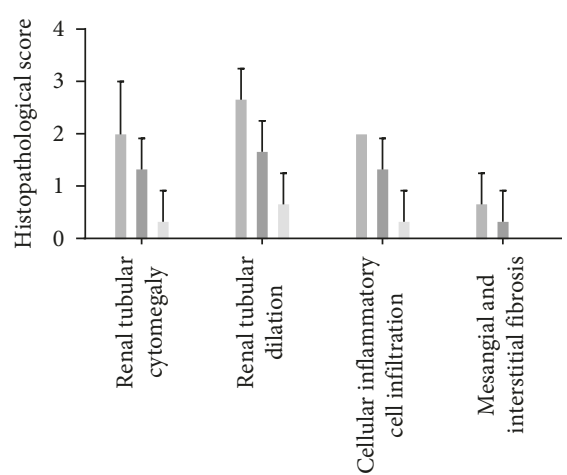

Histopathological changes on the renal tissue

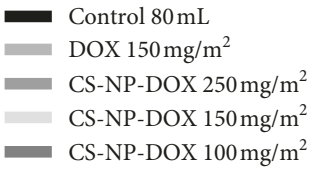

(b)

FIGURE 9: Semiquantitative analysis of both left ventricular myocardial muscle and the renal tissue of the experimental dogs. All the data are expressed as mean \pm SD.

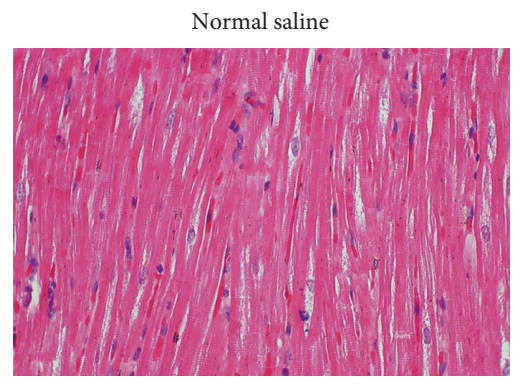

(a)

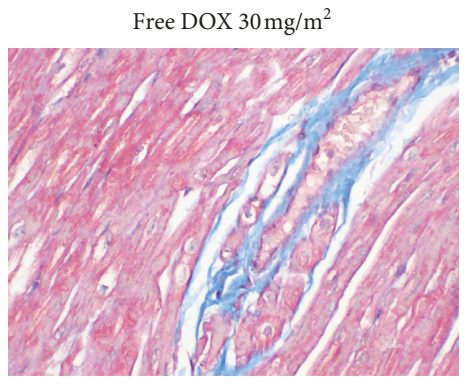

(b)

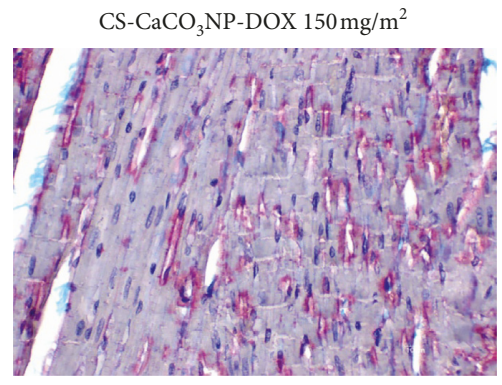

(c)

FIGURE 10: Photomicrograph of the myocardium. (a) Myocardium of the dogs given normal saline showing the normal morphological architecture of myocardial fibres. (b) Free DOX $150 \mathrm{mg} / \mathrm{m}^{2}$ showing collagen deposit within the interstitial myocardial space of myocardial fibres. (c) $\mathrm{CS}-\mathrm{CaCO}_{3} \mathrm{NP}-\mathrm{DOX} 150 \mathrm{mg} / \mathrm{m}^{2}$ showing basophilic cardiomyocytes with the myocardial fibres (Masson's trichrome). Scale bar $10 \mu \mathrm{m}$.

3.7.1. Histochemistry Evaluation of the Effect of Cumulative Doses of DOX and CS-CaCO${ }_{3} \mathrm{NP}-\mathrm{DOX}$ on Cardiac and Hepatic Tissues. The histological sections of the myocardium of both dogs given normal saline and $\mathrm{CS}-\mathrm{CaCO}_{3} \mathrm{NP}-$ DOX at a cumulative dose of $150 \mathrm{mg} / \mathrm{m}^{2}$ and below revealed similar normal morphology. They showed normal distribution of collagen between the myofibrils (Figure 10). However, a marked deposition of collagen fibrils was observed in the interstitial myofibril space between myocardial filaments in dogs given a cumulative dose of free DOX $150 \mathrm{mg} / \mathrm{m}^{2}$ (Figure 10). Moreover, dense collagen matrix was also observed well deposited in the myomysium between the myofibrils and appeared as blue-stained materials in the myocardial tissue (Figure 10).

3.8. Ultrastructural Changes in Cardiac and Kidney Tissues of Dogs Given Cumulative Doses of DOX and CS- $\mathrm{CaCO}_{3} \mathrm{NP}-$ $D O X$. The electron micrograph of the myocardium of dogs given free DOX at a cumulative dose of $150 \mathrm{mg} / \mathrm{m}^{2}$ revealed extensive mitochondrial rupture with marked swelling and cristae disorientation (Figure 11). The orientations of the myofibrils were irregular with vacuolation within the intercellular space of the myofibrils with clusters of electron dense deposit within the sarcomere and intermyofibrillar cytoplasm as shown in Figure 11. In addition, scattered vacuolated cardiomyocyte with free empty vacuum, focal disruption of myofilament, and Z-band aggregate in close cluster to the ribosome in the cytoplasm are indicatives of myofibril loss in the left ventricular electron micrograph of the dogs given free DOX at a cumulative dose of $150 \mathrm{mg} / \mathrm{m}^{2}$ (Figure 11). Similar changes were observed on the TEM of the myocardium in dogs given a higher dose of CS$\mathrm{CaCO}_{3}$ NP-DOX (at a cumulative dose of $250 \mathrm{mg} / \mathrm{m}^{2}$ ), and marked mitochondrial swelling was observed as compared to the ruptured mitochondria in dogs given free DOX at a cumulative dose of $150 \mathrm{mg} / \mathrm{m}^{2}$ (Figure 11), whereas a clear regular orientation of the myofibrils with distinct cisternae on the mitochondria with oval- to spindle-shaped nucleus was observed in the myocardial tissue in dogs given normal 


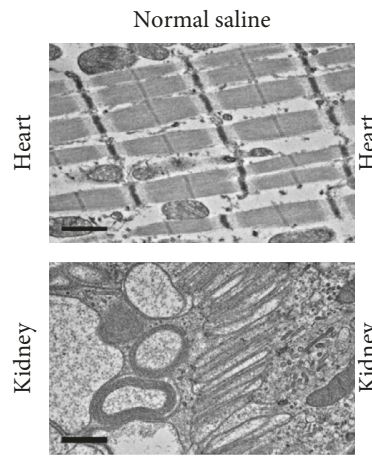

(a)

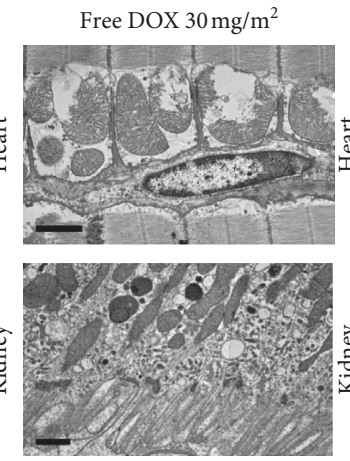

(b)

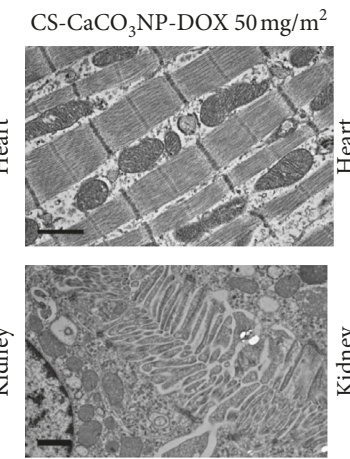

(c)

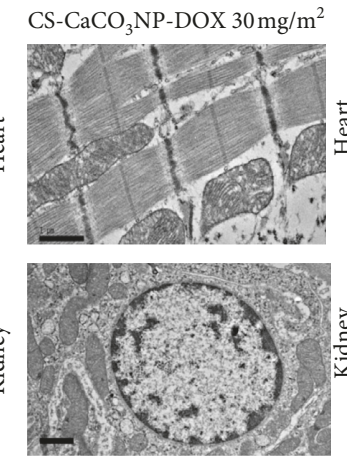

(d)

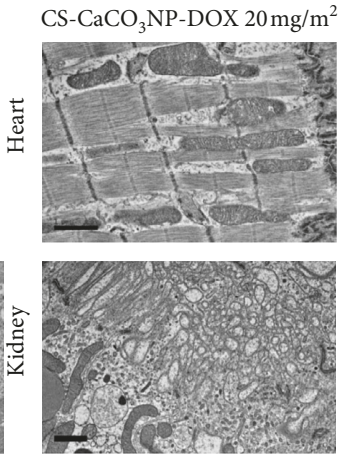

(e)

FIGURE 11: Electron micrograph (TEM) of the left ventricular myocardial tissue section and kidney section. (a) Myocardial tissue section of dogs given normal saline showing clear distinct cisternae on the mitochondria, with spindle-shaped nucleus within the myofilament and the proximal convoluted tubules of the dogs given normal saline revealing its lumen and apical cellular membrane with microvilli appearing normal with distinct mitochondrial cisternae and nerves surrounded by myelin sheaths. (b) Free DOX $150 \mathrm{mg} / \mathrm{m}^{2}$ showing extensive mitochondrial damage and rupture with marked swelling and cristae disorientation, scattered vacuolated cardiomyocyte, with free empty vacuum and $Z$-band aggregate in close cluster to ribosome in the cytoplasm with the dilated proximal convoluted tubules with vesicle and distorted cristae in the mitochondria. (c) $\mathrm{CS}-\mathrm{CaCO}_{3} \mathrm{NP}-\mathrm{DOX} 250 \mathrm{mg} / \mathrm{m}^{2}$ showing mitochondrial rupture with cristae disorientation with free empty vacuum with few dilated proximal convoluted tubules and shrinked apical microvilli and vesicle and sarcoplasmic tubules. (d) $\mathrm{CS}-\mathrm{CaCO}_{3} \mathrm{NP}-\mathrm{DOX} 150 \mathrm{mg} / \mathrm{m}^{2}$ showing clear distinct cisternae on the mitochondria, with sarcoplasmic tubules, myofilament with the renal nucleus with distinct peripheral distribution of chromatic material and normal appearance with mild swollen mitochondrial and rough endoplasmic reticulum with a normal basement membrane thickness. (e) CS-CaCO ${ }_{3} \mathrm{NP}-\mathrm{DOX} 100 \mathrm{mg} / \mathrm{m}^{2}$ showing clear distinct cisternae on the mitochondria, with sarcoplasmic tubules, myofilament with the normal appearance of renal tissue with mild swollen mitochondrial and rough endoplasmic reticulum with a normal basement membrane thickness $(1 \mu \mathrm{m})$.

saline and those given CS- $\mathrm{CaCO}_{3} \mathrm{NP}-\mathrm{DOX}$ at a cumulative dose of $150 \mathrm{mg} / \mathrm{m}^{2}$ and below (Figure 11).

The TEM of renal tissue in the dogs given normal saline revealed normal architectural morphology of the apical region of the proximal convoluted tubules with microvilli membrane associated with distinct mitochondrial cisternae and nerves enveloped by myelin sheaths (Figure 11), which were similar to those given $\mathrm{CS}-\mathrm{CaCO}_{3} \mathrm{NP}-\mathrm{DOX}$ at cumulative dose of $150 \mathrm{mg} / \mathrm{m}^{2}$ and below. Furthermore, the renal nucleus was surrounded by the peripheral distribution of chromatin material in close relation with normal mitochondria, rough endoplasmic reticulum, and basement membrane (Figure 11). However, those given free DOX $150 \mathrm{mg} / \mathrm{m}^{2}$ and CS-CaCO ${ }_{3} \mathrm{NP}-\mathrm{DOX}$ at a cumulative dose of above $150 \mathrm{mg} / \mathrm{m}^{2}$ have dilated proximal convoluted tubules, distorted mitochondrial cisternae, vesicle within the renal cytoplasmic region, and the presence of numerous lysosomes and peroxisomes (Figure 11).

\section{Discussion}

Currently, several innovative developments are witnessed within nanomedicine, specifically in the area of applied medicine [42]. In spite of all the advances in chemotherapeutic formulation development, toxicity of nano-DOX formulation still remains as a major setback, since most of the organic nanocarrier used themselves causes tissue damage [42], leaving oncologist with no other option but rather to amend dose of DOX or combine it with another cytotoxic drug which might not be enough to inhibit the tumour metastasis and growth [1].
The primary goal of this study was to evaluate the safety and toxicity of CS- $\mathrm{CaCO}_{3} \mathrm{NP}-\mathrm{DOX}$ in healthy dogs, which can only be achieved by evaluating tissue injury biomarkers and cytological examination of tissue with more emphasis on the myocardium and kidney tissues. The findings from this study, which is lacking in the scientific literature, will serve as a guide in dose selection, understanding the safety margin of the formulation for clinical application.

Alopecia is a common manifestation of the toxic effect of repeated dose administration of DOX in both clinical and experimental studies [43]. However, the encapsulation of DOX into CS- $\mathrm{CaCO}_{3} \mathrm{NP}$ prevents uncontrolled release and the manifestation of alopecia in the dogs. The hair loss observed in the dogs given free DOX was in agreement with what was reported by Todorova et al. [44] in dogs given repeated doses of $20-30 \mathrm{mg} / \mathrm{m}^{2}$ at the 20th day in the management of the canine mammary tumour.

Generally, a decrease in body weight is an indicator of cellular disturbance and biomarker for safety in toxicity studies as reported by Patel et al. [45] and Chen et al. [46]. It is well known that chemotherapy causes general body weight loss [43]. The body weight loss observed in the dogs given a cumulative dose of free DOX agrees with the report of Boussada et al. [43] in Wister rats and was in line with findings of Sato et al. [47] in mice and DeFrancesco et al. [48] in dogs. In this study, the weight loss is likely to be associated with anorexia, homeostatic body function, and metabolic imbalance of the electrolytes, as seen earlier in rodent given DOX [49].

However, less body weight loss observed with CS$\mathrm{CaCO}_{3} \mathrm{NP}-\mathrm{DOX}$ at a cumulative dose of $150 \mathrm{mg} / \mathrm{m}^{2}$ could be 
attributed to the reduction in bioavailability of DOX as a result of sustained control release of DOX from CS$\mathrm{CaCO}_{3} \mathrm{NP}$ in the body. This eventually helps in reducing the cytotoxic effect associated with free DOX and further explains the safety nature of CS- $\mathrm{CaCO}_{3} \mathrm{NP}-\mathrm{DOX}$ at a cumulative dose of $150 \mathrm{mg} / \mathrm{m}^{2}$ as compared to free DOX at an equivalent dose.

The mild increase in rectal temperature recorded was similar to the earlier reports of Sen et al. [50], where body temperature increased within 5th-9th hours of administration of anticancer in mice. This transient elevation could be associated with the immunological reaction between DOX and the immune cell.

The changes in the blood cells especially erythrocytes, platelets, and leucocyte count were all DOX dose dependent and were consistent with the findings reported by Manno et al. [5]; Tacar et al. [51], which could be attributed to the known bone marrow suppressive effect of DOX and ironDOX interaction, thus causing RBC membrane rupture as previously reported by Vici et al. [52] and Pahouja et al. [53] since DOX did not limit its effects not only to cancer cell alone but also to proliferating haematopoietic cells.

The reduction in leucocytes observed in dogs given free DOX was in agreement with Judson et al. [54], who reported neutropenia and thrombocytopenia with DOX administration. In addition, a similar reduction was observed in $\mathrm{RBC}$ and WBC in DOX-induced toxicity in the mouse [4], cat $[55,56]$, and dogs [57]. It is important to note that direct platelet lysis contributes to the thrombocytopenia as seen earlier with amoxicillin and vincristine which induced platelets lysis and were reported to cause thrombocytopenia $[58,59]$. Interestingly, $\mathrm{CS}-\mathrm{CaCO}_{3} \mathrm{NP}-\mathrm{DOX}$, when given at dose regimen of $30 \mathrm{mg} / \mathrm{m}^{2}$, did not alter the haematological cells as compared to its equivalent doses of free DOX $30 \mathrm{mg} / \mathrm{m}^{2}$. However, when CS-CaCO ${ }_{3} \mathrm{NP}-\mathrm{DOX} 50 \mathrm{mg} / \mathrm{m}^{2}$ is given, it expected that the concentration maximum could be higher after the third dose in circulation which could have resulted in the effect observed.

The serum biochemical evaluation profile provides supportive evidence for the toxicity and safety of $\mathrm{CS}-\mathrm{CaCO}_{3} \mathrm{NP}-$ DOX as compared to the free DOX. The slow release of the DOX from the $\mathrm{CS}-\mathrm{CaCO}_{3} \mathrm{NP}$ might have prevented excessive interaction of the DOX with normal proliferative cells leading to cellular damage due to oxidative reactions [40]. DOX causes disruption of the myocyte membrane, which triggers the release of CK and AST into the peripheral circulation [60], and thus serves as an indicator for muscular tissue injuries, associated with ALT enzymes in the liver which explains the integrity cell membrane [60].

The increase in ALP and AST in the dogs, upon cumulative dose of $120 \mathrm{mg} / \mathrm{m}^{2}$ and above of the free DOX, concords with the reports of Chen et al. [60] and is similar to the findings of Xin et al. [61], in dogs, with AST and CK increase attributed to myocardial disruption due to free oxygen radical release from DOX metabolic pathway.

The increase in AST and ALP with the cumulative dose of free DOX and a higher concentration of CS-CaCO $\mathrm{C}_{3} \mathrm{NP}-\mathrm{DOX}$ above $120 \mathrm{mg} / \mathrm{m}^{2}$ indicate cellular damage to the hepatic cells causes an outflow of the enzymes into the circulation which absolutely correlates with the histological tissue finding observed on the liver.

Swamy et al. [62] reported an increase in $\mathrm{LDH}$ and CK in the early stage of myocardial injury induced by DOX in the mouse. This report was consistent with our finding in $\mathrm{LDH}$ and $\mathrm{CK}$ levels in dogs given free DOX, although the increase in $\mathrm{LDH}$ was not specific for myocardial injury; however, increase in $\mathrm{CK}$ at cumulative dose of free DOX above $120 \mathrm{mg} / \mathrm{m}^{2}$ was observed as compared to its level in the dogs given equivalent cumulative dose of CS-CaCO${ }_{3} \mathrm{NP}-\mathrm{DOX}$, which is suggestive of myocardial injury and renal damage. The alteration in the creatinine and urea in the dogs given cumulative dose of free DOX $150 \mathrm{mg} / \mathrm{m}^{2}$ and higher cumulative dose of CS-CaCO ${ }_{3} \mathrm{NP}-\mathrm{DOX} 250 \mathrm{mg} / \mathrm{m}^{2}$ was similar to what was observed by Han et al. [63] in beagle dogs given 4 weeks repeated dose of camptothecin, which has similar mechanism action with DOX in terms of topoisomerase I enzyme suppression.

cTn-I is currently applied as a specific biomarker for cardiac injury in both humans and animals [64-66]; thus, it is used to access cardiac injury in mini pig $[65,67]$ and rats $[65,68]$. However, the increase in cTn-I level was used to further confirm the histopathological changes on the myocardium. Interestingly, the pattern in which cTn-I level increases was similar to what was observed in the mice given free repeated dose of the DOX $1 \mathrm{mg} / \mathrm{kg}$ with a significant increase in the cTn level in the serum after 42 days with the level reaching a plateau level at 70 days [69].

In addition, NT-proBNP is also complimentary diagnostic assay for the monitoring and evaluating cardiac injury regardless of whether it is congestive heart failure or not [70, 71], although less specific to cTn-I. In a similar works, Wu et al. [70] reported an increase in the BNP serum concentration in rat in both short- and long-term repeated doses of DOX toxicity studies. However, vertebral heart score was used to evaluate heart size within the thoracic cavity. The mean increase in the heart size of the dogs given free DOX at a cumulative dose of $150 \mathrm{mg} / \mathrm{m}^{2}$ as compared to the dogs given $\mathrm{CS}-\mathrm{CaCO}_{3} \mathrm{NP}$-DOX agrees with the findings of Nakayama et al. [72] in the dogs, where VHS was used to assess heart size. However, cardiac silhouettes observed increases the opacity for cardiac radiograph which concurs with the findings by Guglielmini et al. [73], where fluid increases the opacity and changes the size and shape of cardiac silhouettes in the dogs with congestive heart failure.

Electrocardiography presently serves as a monitoring tool for cardiac safety assessment; however, several clinical cardiac safety assessments applied this tool to detect abnormal conductivity of the heart [7]. In this study, significant changes were observed, showing clear indication of the supraventricular arrhythmia and systolic dysfunction with ventricular enlargement which are suggestive of cardiomyopathy. The changes in QRS complex, QRS axis, and QT interval in dogs given cumulative dose of free DOX $150 \mathrm{mg} / \mathrm{m}^{2}$ were consistent with the changes in DOXinduced myocardial injury reported by Kulkarni and Swamy [7] and were in agreement with reports of $\mathrm{Wu}$ et al. [70] in rats and Pereira Neto et al. [74] in healthy dogs. These were all signs of either supraventricular or ventricular 
arrhythmias, thus a manifestation of cardiomyopathy, which could be attributed to the myofibril disruption and myofilament disorientation impulse blockage on the heart. However, encapsulation CS-CaCO${ }_{3} \mathrm{NP}-\mathrm{DOX}$ with a slow release of DOX could have prevented myocardial injury.

The supraventricular arrhythmia observed was doserelated, which could be due to multiple actions of DOX on cardiac electrophysiological activities; however, these findings were similar to the reports of Pereira Neto et al. [74] in dogs with signs of myocardial dysfunctions at a cumulative dose of DOX above $150 \mathrm{mg} / \mathrm{m}^{2}$.

The increase in the heart weight-to-body weight ratio in dogs given free DOX might be attributed to decrease in the body weight. This finding was consistent with the report of Swamy et al. [62]. Thus, the enlargement of the sarcoplasmic reticulum and mitochondrial swelling could be attributed to the increase in the heart weight-to-body weight ratio as the structural changes are often observed in DOX-induced cardiomyopathy [7].

The left ventricular wall thickness agrees with the reports of Nakayama et al. [72] that ventricular wall thinning is associated with dilated cardiomyopathy. In addition, the changes in the myocardium conform with the findings reported by Noda et al. [75] and Working et al. [76] that DOXinduced cardiotoxicity possesses unique features different from other cardiac injuries such as myocardial vacuolation, oedema, and myofibrillar membrane damage associated with interstitial fibrosis. These histopathological changes could be as a result of the free radical release from irondependent interaction and deregulation of the calcium channel pump with the myocytes leading to uncontrol reflux within and outside the cells.

The normal histological structure of the myocardial tissue in dogs given CS- $\mathrm{CaCO}_{3} \mathrm{NP}-\mathrm{DOX}$ at cumulative dose of $150 \mathrm{mg} / \mathrm{m}^{2}$ and below further provides evidence that no cardiotoxicity was induced on the myocardial tissue in the dogs which were similar to the finding observed by Rahman et al. [77] in rabbit given DOX encapsulated in liposomal polymeric nanocarrier. The myocardial disorientation observed in the dogs given CS-CaCO${ }_{3} \mathrm{NP}-\mathrm{DOX}$ at a higher cumulative dose of above $200 \mathrm{mg} / \mathrm{m}^{2}$ concurs with the finding of Yang et al. [78] in the healthy rats and Maksimenko et al. [69] in mice since the concentration of DOX release from $\mathrm{CS}-\mathrm{CaCO}_{3} \mathrm{NP}$ was very low to cumulatively elicit direct cellular injury.

Furthermore, the interstitial fibrosis observed in the myocardial tissue of the dogs given free DOX and higher dose of CS- $\mathrm{CaCO}_{3}$ NP-DOX (at cumulative dose of $250 \mathrm{mg} / \mathrm{m}^{2}$ ) was in agreement with chronic model showing cardiomyocyte damage and fibrosis $[79,80]$, which could be as a result of cardiomyocyte compensatory action toward regeneration of myofiber undergoing degeneration or necrosis.

The kidney is a major excretory organ and is directly targeted by anthracycline, causing nephrotoxicity manifested as parenchyma and cellular damage [81]. However, the carrier molecules are entrapped within the slit diaphragm due to the size of the carrier molecules used in drug delivery leading to renal tubular tissue injury [82]. The glomerular and tubular damage observed in our study was similar to the lesion seen in rodent as reported by Cianciolo et al. [83] and Manno et al. [5] in rodent and mini pig animal models, respectively. In addition, our results also agree with the works of Anan et al. [84] as clusters of nuclear material were observed as a result of free radical production from lipid peroxidation.

Shivakumar et al. [85] reported that DOX has the potential to induce kidney tissue injury resulting from glomerulonephritis as observed in this study. The mechanism by which DOX induces nephrotoxicity shares similar pathway to that of cardiotoxicity which is induced through multifactorial pathways, ranging from oxidative stress, mitochondrial dysfunction, changes in transduction pathway [86]. One of the basic informative cellular changes observed due to DOX-induced damage is on the mitochondrial conformation as revealed by the ultrastructural examination of both cardiac muscle and renal tissue. Similarly, cardiorenal toxic effects were reported by Pereira et al. [87] and Berthiaume et al. [88] when repeated free DOX was administered, and myofibrillar disorientation and myocardial vacuolation with swallow to ruptured mitochondria were observed in cardiac tissue in the healthy animal model. However, interestingly, in this work, doses suggested for repeated dose administration of clinical dose regimens of CS-CaCO${ }_{3} \mathrm{NP}-\mathrm{DOX} 30 \mathrm{mg} / \mathrm{m}^{2}$ for 5 treatments did not witness any cardiorenal toxic effect resulting in cardiorenal structural and functional changes as compared to the dogs given an equivalent dose to free DOX $30 \mathrm{mg} / \mathrm{m}^{2}$.

The presence of adria cells observed in dogs was as a result of sarcoplasmic reticulum dilation as reported by Attia et al. [89] on the myocardial tissue damage. All the changes observed conform with the lesions observed histopathologically, on the light microscopes, and were similar to the previous reports in DOX-induced cardiotoxicity $[89,90]$.

The cardiac muscle of the dogs given a repeated dose of CS- $\mathrm{CaCO}_{3} \mathrm{NP}-\mathrm{DOX}$ at a cumulative dose of $150 \mathrm{mg} / \mathrm{m}^{2}$ and at clinical regiment dose of $30 \mathrm{mg} / \mathrm{m}^{2}$ did not show any significant ultrastructural changes similar to the morphological architecture observed on the light microscopy. This was due to the small amount of DOX at sustained concentration released from the CS- $\mathrm{CaCO}_{3} \mathrm{NP}-\mathrm{DOX}$ in normal physiological microenvironment as reported in the in vitro assay [18]. However, in contrary to the findings reported by Dhingra et al. [91] in mitochondrial signal, DOX induce necrosis in mice.

The kidney is also a targeted organ for DOX as previously reported by Salouege et al. [92] and Cianciolo et al. [83], but the order of the DOX organ affinity is less when compared to the heart due to cardiolipin concentration. Zhou et al. [93] demonstrated that the apical region of proximal tubules which have microvillus and abundant podocytes was responsible for the secretion of nephrin and podocin, which are structural components of slit diaphragm. The ultrastructural changes observed were similar to the changes reported by Ayla et al. [94] and Tao et al. [95] in their work, with clear visible vacuolization of the endothelial cells with thickening of the glomerular basement membrane and apoptosis of the podocyte foot processes. The degeneration 
of the foot process of the podocytes observed further confirms the glomerular obliteration of the corpuscular space observed on the same tissue in the histopathological analysis.

\section{Conclusion}

In conclusion, this study revealed that DOX-loaded cockleshell-derived $\mathrm{CaCO}_{3} \mathrm{NP}$ has less cardiotoxicity and nephropathic effects at a higher cumulative dose $\left(250 \mathrm{mg} / \mathrm{m}^{2}\right)$ as compared to the free DOX in healthy dogs. Thus, the study indicates that $\mathrm{CS}-\mathrm{CaCO}_{3} \mathrm{NP}$ can minimize the off-target effects of the DOX in dogs with the aim of increasing quality of life in dogs that needs long-term therapeutic regime. This study further revealed the safety and tolerance of repeated dose administration of the CS$\mathrm{CaCO}_{3} \mathrm{NP}$-DOX in healthy dogs due to low amount of DOX exposure to vital organs, thus reducing the risk of cardiotoxicity and nephrotoxicity.

\section{Data Availability}

The datasets generated and/or analysed during the current study are available from the corresponding author on reasonable request.

\section{Ethical Approval}

The protocols used in this study all were in line with the guidelines of international animal care and committee units.

\section{Conflicts of Interest}

There were no conflicts of interest among authors of this article.

\section{Acknowledgments}

The authors acknowledge the assistance of Dato Dr. Azmi Tengku Ibrahim for the ultrastructural tissue interpretation and evaluation and Mr. Hilman of the Animal Research Facility UPM for his technical support in animal handling and drug delivery. This work was financially supported by Prototype Development Research Grant Scheme (PRGS 5532300) of the Malaysian Ministry of Higher Education.

\section{References}

[1] Y. González-Fernández, E. Imbuluzqueta, M. Zalacain, F. Mollinedo, A. Patiño-García, and M. J. Blanco-Prieto, "Doxorubicin and edelfosine lipid nanoparticles are effective acting synergistically against drug-resistant osteosarcoma cancer cells," Cancer Letters, vol. 388, pp. 262-268, 2017.

[2] V. Jacevic, A. Djordjevic, B. Srdjenovic et al., "Fullerenol nanoparticles prevents doxorubicin-induced acute hepatotoxicity in rats," Experimental and Molecular Pathology, vol. 102, no. 2, pp. 360-369, 2017.

[3] B. S. Kadu, K. D. Wani, R. Kaul-Ghanekar, and R. C. Chikate, "Degradation of doxorubicin to non-toxic metabolites using Fe-Ni bimetallic nanoparticles," Chemical Engineering Journal, vol. 325, pp. 715-724, 2017.
[4] V. G. Desai, E. H. Herman, C. L. Moland et al., "Development of doxorubicin-induced chronic cardiotoxicity in the B6C3F1," Toxicology and Applied Pharmacology, vol. 266, pp. 109-121, 2013.

[5] R. A. Manno, A. Grassetti, G. Oberto, A. Nyska, and Y. Ramot, "The minipig as a new model for the evaluation of doxorubicin-induced chronic toxicity," Journal of Applied Toxicology, vol. 36, no. 8, pp. 1060-1072, 2016.

[6] S. K. Nimbal and B. C. Koti, "Cardioprotective effect of Rosa centifolia against doxorubicin-induced myocardial toxicity in albino rats," RGUHS Journal of Pharmaceutical Sciences, vol. 6, no. 1, pp. 12-19, 2016.

[7] J. M. Kulkarni and A. H. M. V. Swamy, "Cardioprotective effect of gallic acid against doxorubicin-induced myocardial toxicity in albino rats," Indian Journal of Health Sciences, vol. 8, no. 1, pp. 28-35, 2015.

[8] F. Yarmohmmadi, N. Rahimi, H. Faghir-Ghanesefat et al., "Protective effects of agmatine on doxorubicin-induced chronic cardiotoxicity in rat," European Journal of Pharmacology, vol. 796, pp. 39-44, 2017.

[9] D. Lebrecht, A. Geist, U.-P. Ketelsen, J. Haberstroh, B. Setzer, and U. A. Walker, "Dexrazoxane prevents doxorubicin-induced long-term cardiotoxicity and protects myocardial mitochondria from genetic and functional lesions in rats," British Journal of Pharmacology, vol. 151, no. 6, pp. 771-778, 2007.

[10] D. Lebrecht, A. Kokkori, U. P. Ketelsen, B. Setzer, and U. A. Walker, "Tissue-specific mtDNA lesions and radicalassociated mitochondrial dysfunction in human hearts exposed to doxorubicin," Journal of Pathology, vol. 207, no. 4, pp. 436-444, 2005.

[11] P. I. P. Soares, A. I. Sousa, J. C. Silva, I. M. M. Ferreira, C. M. M. Novo, and J. P. Borges, "Chitosan-based nanoparticles as drug delivery systems for doxorubicin: optimization and modelling," Carbohydrate Polymers, vol. 147, pp. 304-312, 2016.

[12] G. Bozzuto and A. Molinari, "Liposomes as nanomedical devices," International Journal of Nanomedicine, vol. 10, pp. 975-999, 2015.

[13] X. Liu, A. Situ, Y. Kang et al., "Irinotecan delivery by lipidcoated mesoporous silica nanoparticles shows improved efficacy and safety over liposomes for pancreatic cancer," ACS Nano, vol. 10, no. 2, pp. 2702-2715, 2016.

[14] R. H. Prabhu, V. B. Patravale, and M. D. Joshi, "Polymeric nanoparticles for targeted treatment in oncology: current insights," International Journal of Nanomedicine, vol. 10, pp. 1001-1018, 2015.

[15] M. Alibolandi, K. Abnous, M. Mohammadi et al., "Extensive preclinical investigation of polymersomal formulation of doxorubicin versus Doxil-mimic formulation," Journal of Controlled Release, vol. 264, pp. 228-236, 2017.

[16] B. Kumar, K. Jalodia, P. Kumar, and H. K. Gautam, "Recent advances in nanoparticle-mediated drug delivery," Journal of Drug Delivery Science and Technology, vol. 41, pp. 260-268, 2017.

[17] L. Zhang, F. Gu, J. Chan, A. Wang, R. Langer, and O. Farokhzad, "Nanoparticles in medicine: therapeutic applications and developments," Clinical Pharmacology \& Therapeutics, vol. 83, no. 5, pp. 761-769, 2008.

[18] W. Fu, M. N. M Hezmee, L. M. Yusof et al., "In vitro evaluation of a novel $\mathrm{pH}$ sensitive drug delivery system based cockle shell-derived aragonite nanoparticles against osteosarcoma," Journal of Experimental Nanoscience, vol. 12, no. 1, pp. 166-186, 2017. 
[19] N. I. Hammadi, Y. Abba, M. N. M. Hezmee et al., "Formulation of a sustained release docetaxel loaded cockle shell-derived calcium carbonate nanoparticles against breast cancer," Pharmaceutical Research, vol. 34, no. 6, pp. 1193-1203, 2017.

[20] M. M. Joseph, S. R. Aravind, S. K. George, K. Raveendran Pillai, S. Mini, and T. T. Sreelekha, "Galactoxyloglucanmodified nanocarriers of doxorubicin for improved tumortargeted drug delivery with minimal toxicity," Journal of Biomedical Nanotechnology, vol. 10, no. 11, pp. 3253-3268, 2014.

[21] M. B. Gugjoo, M. Hoque, A. C. Saxena, and M. M. Sham-Suz Zama, "Reference values of six-limb-lead electrocardiogram in conscious Labrador Retriever dogs," Pakistan Journal of Biological Sciences, vol. 17, no. 5, pp. 689-695, 2014.

[22] M. L. Hauck, S. M. La Rue, W. P. Petros et al., "Phase I trial of doxorubicin-containing low temperature sensitive liposomes in spontaneous canine tumors," Clinical Cancer Research, vol. 12, no. 13, pp. 4004-4010, 2006.

[23] S. L. Gillings, L. Sarah, J. Johnson, A. Fulmer, and M. Hauck, "Effect of a 1-hour IV infusion of doxorubicin on the development of cardiotoxicity in dogs as evaluated by electrocardiography and echocardiography," Veterinary Therapeutics, vol. 10, no. 1, pp. 46-58, 2009.

[24] E. S. Christenson, T. James, V. Agrawal, and B. H. Park, "Use of biomarkers for the assessment of chemotherapy-induced cardiac toxicity," Clinical Biochemistry, vol. 48, no. 4-5, pp. 223-235, 2015.

[25] M. A. Oyama, "Using cardiac biomarkers in veterinary practice," Veterinary Clinics of North America: Small Animal Practice, vol. 43, no. 6, pp. 1261-1272, 2013.

[26] A. Danmaigoro, G. T. Selvarajah, M. H. M. Noor, R. Mahmud, and M. Z. Abu Bakar, "Development of cockleshell (Anadara granosa) derived $\mathrm{CaCO}_{3}$ nanoparticle for doxorubicin delivery," Journal of Computational and Theoretical Nanoscience, vol. 14, no. 10, pp. 5074-5086, 2017.

[27] K. Iohara, M. Murakami, K. Nakata, and M. Nakashima, "Age-dependent decline in dental pulp regeneration after pulpectomy in dogs," Experimental Gerontology, vol. 52, pp. 39-45, 2014.

[28] Institute for Laboratory Animal Research, Guide for the Care and Use of Laboratory Animals, ILAR, Washington DC, USA, 8th edition, 2011.

[29] J. J. DeGeorge, L. L. Meyers, M. Takahashi, and J. F. Contrera, "The duration of non-rodent toxicity studies for pharmaceuticals," Toxicological Sciences, vol. 49, no. 2, pp. 143-155, 1999.

[30] A. P. Théon, N. Pusterla, K. G. Magdesian, and W. D. Wilson, "Phase I dose escalation of doxorubicin chemotherapy in tumor-bearing equidae," Journal of Veterinary Internal Medicine, vol. 27, no. 5, pp. 1209-1217, 2013.

[31] A. G. Chang, J. Hu, E. Lake, D. M. Bouley, and J. L. Johns, "Biochemical and hematologic reference intervals for aged Xenopus laevis in a research colony," Journal of the American Association for Laboratory Animal Science, vol. 54, no. 5, pp. 465-470, 2015.

[32] J. A. Cartwright, D. J. Gow, A. G. Gow et al., "Serum cardiac troponin I concentrations decrease following treatment of primary immune-mediated haemolytic anaemia," Journal of Small Animal Practice, vol. 56, no. 8, pp. 516-520, 2015.

[33] H. Sawaya, I. A. Sebag, J. C. Plana et al., "Assessment of echocardiography and biomarkers for the extended prediction of cardiotoxicity in patients treated with anthracyclines, taxanes, and trastuzumab," Circulation: Cardiovascular Imaging, vol. 5, no. 5, pp. 596-603, 2012.
[34] E. G. Gülanber, R. Gönenci, Ü. Kaya, Ö. Aksoy, and H. S. Biricik, "Vertebral scale system to measure heart size in thoracic radiographs of Turkish shepherd (Kangal) dogs," Turkish Journal of Veterinary and Animal Sciences, vol. 29, no. 3, pp. 723-726, 2005.

[35] S. D. Surachetpong and P. Teewasutrakul, "Serial measurements of cardiac troponin I (cTnI) in dogs treated with doxorubicin," Japanese Journal of Veterinary Research, vol. 64, no. 4, pp. 221-233, 2016.

[36] R. C. Alves de Souza and A. A. Camacho, "Neurohormonal, hemodynamic, and electrocardiographic evaluations of healthy dogs receiving long-term administration of doxorubicin," American Journal of Veterinary Research, vol. 67, no. 8, pp. 1319-1325, 2006.

[37] G. E. Mauldin, P. R. Fox, A K. Patnaik, B. R. Bond, S. C. Mooney, and R. E. Matus, "Doxorubicin-induced cardiotoxicosis clinical features in 32 dogs," Journal of Veterinary Internal Medicine, vol. 6, no. 2, pp. 82-88, 1992.

[38] R. Fracasso, M. Baierle, G. Goëthel et al., "Evaluation of potential acute cardiotoxicity of biodegradable nanocapsules in rats by intravenous administration," Toxicology Research, vol. 5, no. 1, pp. 168-179, 2016.

[39] S. Schäfer-Somi, K. Deichsel, H. Beceriklisoy, D. Korkmaz, I. Walter, and S. Aslan, "Morphological, histological and molecular investigations on canine uterine tissue after ovariectomy," Theriogenology, vol. 102, pp. 80-86, 2017.

[40] M. Erboga, Y. Bozdemir Donmez, U. Sener, Z. Fidanol Erboga, C. Aktas, and M. Kanter, "Effect of urtica dioica against doxorubicin-induced cardiotoxicity in rats through suppression of histological damage, oxidative stress and lipid peroxidation," European Journal of General Medicine, vol. 13, no. 2, pp. 139-144, 2016.

[41] N. A. Bakar, T. A. T. Ibrahim, N. A. Mohamad Shalan, and S. Mohamed, "Changes in rats' breast tumor ultrastructure and immune and messenger RNA responses caused by dietary Seaweed (Kappaphycus alvarezii) extract," Journal of Microscopy and Ultrastructure, vol. 5, no. 2, pp. 70-81, 2017.

[42] L. Cabeza, R. Ortiz, J. Prados et al., "Improved antitumor activity and reduced toxicity of doxorubicin encapsulated in poly( $\varepsilon$-caprolactone) nanoparticles in lung and breast cancer treatment: an in vitro and in vivo study," European Journal of Pharmaceutical Sciences, vol. 102, pp. 24-34, 2017.

[43] M. Boussada, R. Ben Ali, A. Ben Said et al., "Selenium and a newly synthesized Thiocyanoacetamide reduce Doxorubicin gonadotoxicity in male rat," Biomedicine \& Pharmacotherapy, vol. 89, pp. 1005-1017, 2017.

[44] I. Todorova, G. Simeonova, R. Simeonov, and D. Dinev, "Efficacy and toxicity of doxorubicin and cyclophosphamide chemotherapy in dogs with spontaneous mammary tumours," Trakia Journal of Sciences, vol. 3, no. 5, pp. 51-58, 2005.

[45] V. Patel, A. Upaganlawar, R. Zalawadia, and R. Balaraman, "Cardioprotective effect of melatonin against isoproterenol induced myocardial infarction in rats: a biochemical, electrocardiographic and histoarchitectural evaluation," European Journal of Pharmacology, vol. 644, no. 1-3, pp. 160-168, 2010.

[46] Y. Chen, W. Yang, B. Chang, H. Hu, X. Fang, and X. Sha, "In vivo distribution and antitumor activity of doxorubicinloaded N-isopropylacrylamide-co-methacrylic acid coated mesoporous silica nanoparticles and safety evaluation," European Journal of Pharmaceutics and Biopharmaceutics, vol. 85, no. 3, pp. 406-412, 2013.

[47] K. Sato, K. Sueoka, R. Tanigaki et al., "Green tea extracts attenuate doxorubicin-induced spermatogenic disorders in conjunction with higher telomerase activity in mice," Journal 
of Assisted Reproduction and Genetics, vol. 27, no. 8, pp. 501-508, 2010.

[48] T. C. DeFrancesco, C. E. Atkins, B. W. Keene, J. R. Coats, and M. L. Hauck, "Prospective clinical evaluation of serum cardiac troponin $\mathrm{T}$ in dogs admitted to a Veterinary Teaching Hospital," Journal of Veterinary Internal Medicine, vol. 16, no. 5, pp. 553-557, 2002.

[49] S. K. Bjelogrlic, S. T. Lukic, and S. M. Djuricic, "Activity of dexrazoxane and amifostine against late cardiotoxicity induced by the combination of doxorubicin and cyclophosphamide in vivo," Basic \& Clinical Pharmacology \& Toxicology, vol. 113, no. 4, pp. 228-238, 2013.

[50] A. Sen, M. L. Capitano, J. A. Spernyak et al., "Mild elevation of body temperature reduces tumor interstitial fluid pressure and hypoxia and enhances efficacy of radiotherapy in murine tumor models," Cancer Research, vol. 71, no. 11, pp. 38723880, 2011.

[51] O. Tacar, P. Sriamornsak, and C. R. Dass, "Doxorubicin: an update on anticancer molecular action, toxicity and novel drug delivery systems," Journal of Pharmacy and Pharmacology, vol. 65, no. 2, pp. 157-170, 2013.

[52] P. Vici, G. Colucci, F. Giotta et al., "A multicenter prospective phase II randomized trial of epirubicin/vinorelbine versus pegylated liposomal doxorubicin/vinorelbine as first-line treatment in advanced breast cancer: a GOIM study," Journal of Experimental \& Clinical Cancer Research, vol. 30, no. 1, p. 39, 2011.

[53] G. Pahouja, R. Wesolowski, R. Reinbolt et al., "Stabilization of bone marrow infiltration by metastatic breast cancer with continuous doxorubicin," Cancer Treatment Communications, vol. 3, pp. 28-32, 2015.

[54] I. Judson, J. Verweij, H. Gelderblom et al., "Doxorubicin alone versus intensified doxorubicin plus ifosfamide for first-line treatment of advanced or metastatic soft-tissue sarcoma: a randomised controlled phase 3 trial," The Lancet Oncology, vol. 15, no. 4, pp. 415-423, 2014.

[55] R. A. Reiman, G. E. Mauldin, and G. Neal Mauldin, "A comparison of toxicity of two dosing schemes for doxorubicin in the cat," Journal of Feline Medicine and Surgery, vol. 10, no. 4, pp. 324-331, 2008.

[56] A. N. Schnelle and A. M. Barger, "Neutropenia in dogs and cats: causes and consequences," Veterinary Clinics of North America-Small Animal Practice, vol. 42, no. 1, pp. 111-122, 2012.

[57] L. I. Astra, R. Hammond, K. Tarakji, and L. W. Stephenson, "Doxorubicin-induced canine CHF: advantages and disadvantages," Journal of Cardiac Surgery, vol. 18, no. 4, pp. 301-306, 2003.

[58] E. J. Kim, K. M. Lim, K. Y. Kim et al., "Doxorubicin-induced platelet cytotoxicity: A new contributory factor for doxorubicinmediated thrombocytopenia," Journal of Thrombosis and Haemostasis, vol. 7, no. 7, pp. 1172-1183, 2009.

[59] S. L. Wang, J. J. Lee, and A. T. Liao, "Chemotherapy-induced neutropenia is associated with prolonged remission duration and survival time in canine lymphoma," Veterinary Journal, vol. 205, no. 1, pp. 69-73, 2015.

[60] S. H. Chen, N.-L. Chan, and T. Hsieh, "New mechanistic and functional insights into DNA topoisomerases," Annual Review of Biochemistry, vol. 82, no. 1, pp. 139-170, 2013.

[61] Y. Xin, S. Zhang, L. Gu et al., "Electrocardiographic and biochemical evidence for the cardioprotective effect of antioxidants in acute doxorubicin-induced cardiotoxicity in the beagle dogs," Biological \& Pharmaceutical Bulletin, vol. 34, no. 10, pp. 1523-1526, 2011.
[62] A. V. Swamy, S. Gulliaya, A. Thippeswamy, B. C. Koti, and D. V. Manjula, "Cardioprotective effect of curcumin against doxorubicin-induced myocardial toxicity in albino rats," Indian Journal of Pharmacology, vol. 44, no. 1, pp. 73-77, 2012.

[63] S. C. Han, D. G. Kim, E. H. Han, Y. B. Kim, I. C. Hwang, and C. Y. Kim, "Toxicity study of a new camptothecin anti-cancer agent CKD-602 in dogs: 4-week continuous intravenous dose by infusion pump and 4-week repeated intravenous dose," Regulatory Toxicology and Pharmacology, vol. 58, no. 2, pp. 275-284, 2010.

[64] M. Adamcova, O. Popelova-Lencova, E. Jirkovsky, F. Simko, V. Gersl, and M. Sterba, "Cardiac troponins-translational biomarkers in cardiology: theory and practice of cardiac troponin high-sensitivity assays," BioFactors, vol. 42, no. 2, pp. 133-148, 2016.

[65] W. J. Reagan, R. Barnes, P. Harris et al., "Assessment of cardiac troponin I responses in nonhuman primates during restraint, blood collection, and dosing in preclinical safety studies," Toxicologic Pathology, vol. 45, no. 2, pp. 335-343, 2017.

[66] S. L. Belsey and R. J. Flanagan, "Postmortem biochemistry: current applications," Journal of Forensic and Legal Medicine, vol. 41, pp. 49-57, 2016.

[67] L. Pelander, J. Häggström, C. J. Ley, and I. Ljungvall, "Cardiac troponin I and amino-terminal pro B-type natriuretic peptide in dogs with stable chronic kidney disease," Journal of Veterinary Internal Medicine, vol. 31, no. 3, pp. 805-813, 2017.

[68] K. L. Pokrzywinski, E. T. Rosen, J. Bonanno et al., "Reproductive hormone levels modulate doxorubicin induced cardiomyopathy in female tumor-bearing spontaneously hypertensive rats," Cancer Research, vol. 76, no. 14, p. 4639, 2016.

[69] A. Maksimenko, F. Dosio, J. Mougin et al., "A unique squalenoylated and nonpegylated doxorubicin nanomedicine with systemic long-circulating properties and anticancer activity.," Proceedings of the National Academy of Sciences, vol. 111, no. 2, pp. E217-E226, 2014.

[70] R. Wu, H. L. Wang, H. L. Yu et al., "Doxorubicin toxicity changes myocardial energy metabolism in rats," ChemicoBiological Interactions, vol. 244, pp. 149-158, 2016.

[71] M. A. Oyama, P. R. Fox, J. E. Rush, E. A. Rozanski, and M. Lesser, "Clinical utility of serum N-terminal pro-B-type natriuretic peptide concentration for identifying cardiac disease in dogs and assessing disease severity," Journal of the American Veterinary Medical Association, vol. 232, no. 10, pp. 1496-1503, 2008.

[72] H. Nakayama, T. Nakayama, and R. L. Hamlin, "Correlation of cardiac enlargement as assessed by vertebral heart size and echocardiographic and electrocardiographic findings in dogs with evolving cardiomegaly due to rapid ventricular pacing," Journal of Veterinary Internal Medicine, vol. 15, no. 3, pp. 217-221, 2001.

[73] C. Guglielmini, A. Diana, G. Santarelli et al., "Accuracy of radiographic vertebral heart score and sphericity index in the detection of pericardial effusion in dogs," Journal of the American Veterinary Medical Association, vol. 241, no. 8, pp. 1048-1055, 2012.

[74] G. B. Pereira Neto, J. N. B. Andrade, M. G. Sousa, and A. A. Camacho, "Holter electrocardiography in dogs showing doxorubicin-induced dilated cardiomyopathy," Arquivo Brasileiro de Medicina Veterinária e Zootecnia, vol. 58, no. 6, pp. 1037-1042, 2006. 
[75] T. Noda, T. Watanabe, A. Kohda, S. Hosokawa, and T. Suzuki, "Chronic effects of a novel synthetic anthracycline derivative (SM-5887) on normal heart and doxorubicin-induced cardiomyopathy in beagle dogs," Investigational New Drugs, vol. 16, no. 2, pp. 121-128, 1998.

[76] P. K. Working, M. S. Newman, T. Sullivan, and J. Yarrington, "Reduction of the cardiotoxicity of doxorubicin in rabbits and dogs by encapsulation in long-circulating, pegylated liposomes," Journal of Pharmacology and Experimental Therapeutics, vol. 289, no. 2, pp. 1128-1133, 1999.

[77] A. M. Rahman, S. W. Yusuf, and M. S. Ewer, "Anthracyclineinduced cardiotoxicity and the cardiac-sparing effect of liposomal formulation," International Journal of Nanomedicine, vol. 2, no. 4, pp. 567-583, 2007.

[78] F. Yang, W. Ai, F. Jiang, X. Liu, Z. Huang, and S. Ai, "Preclinical evaluation of an epidermal growth factor receptor-targeted doxorubicin-peptide conjugate: toxicity, biodistribution, and efficacy in Mice," Journal of Pharmaceutical Sciences, vol. 105, no. 2, pp. 639-649, 2016.

[79] J. L. O’Connell, M. M. D. Romano, E. C. Campos Pulici et al., "Short-term and long-term models of doxorubicin-induced cardiomyopathy in rats: A comparison of functional and histopathological changes," Experimental and Toxicologic Pathology, vol. 69, no. 4, pp. 213-219, 2017.

[80] M. R. N. Celes, L. M. Malvestio, S. O. Suadicani et al., "Disruption of calcium homeostasis in cardiomyocytes underlies cardiac structural and functional changes in severe sepsis," PLoS One, vol. 8, no. 7, Article ID e68809, 2013.

[81] Y. R Lee, M. H. Kang, and H. M. Park, "Anthracyclineinduced cardiomyopathy in a dog treated with epirubicin," Canadian Veterinary Journal, vol. 56, no. 1, pp. 539-542, 2015.

[82] E. J. Park, H. K. Kwon, Y. M. Choi, H. J. Shin, and S. Choi, "Doxorubicin induces cytotoxicity through upregulation of pERK-dependent ATF3," PLoS One, vol. 7, no. 9, Article ID e44990, 2012.

[83] R. Cianciolo, L. Yoon, D. Krull et al., "Gene expression analysis and urinary biomarker assays reveal activation of tubulointerstitial injury pathways in a rodent model of chronic proteinuria (Doxorubicin nephropathy)," Nephron Experimental Nephrology, vol. 124, no. 1-2, pp. 1-10, 2012.

[84] H. H. Anan, R. A. Zidan, M. A. Shaheen, and E. A. Abd-El Fattah, "Therapeutic efficacy of bone marrow derived mesenchymal stromal cells versus losartan on adriamycin-induced renal cortical injury in adult albino rats.," Cytotherapy, vol. 18, no. 8, pp. 970-984, 2016.

[85] P. Shivakumar, M. U. Rani, A. G. Reddy, and Y. Anjaneyulu, "A study on the toxic effects of Doxorubicin on the histology of certain organs," Toxicology International, vol. 19, no. 3, pp. 241-244, 2012.

[86] N. M. Elsherbiny and M. El-Sherbiny, "Thymoquinone attenuates doxorubicin-induced nephrotoxicity in rats: role of Nrf2 and NOX4," Chemico-Biological Interactions, vol. 223, pp. 102-108, 2014.

[87] G. C. Pereira, S. P. Pereira, C. V. Pereira et al., "Mitochondrionopathy phenotype in doxorubicin-treated wistar rats depends on treatment protocol and is cardiac-specific," PLoS One, vol. 7, no. 6, Article ID e38867, 2012.

[88] J. M. Berthiaume, P. J. Oliveira, M. W. Fariss, and K. B. Wallace, "Dietary vitamin E decreases doxorubicininduced oxidative stress without preventing mitochondrial dysfunction," Cardiovascular Toxicology, vol. 5, no. 3, pp. 257-267, 2005.
[89] G. M. Attia, R. A. Elmansy, S. A. Algaidi et al., "Silymarin decreases the expression of VEGF-A, iNOS and caspase- 3 and preserves the ultrastructure of cardiac cells in doxorubicin induced cardiotoxicity in rats: a possible protective role," International Journal of Clinical and Experimental Medicine, vol. 10, no. 2, pp. 4158-4173, 2017.

[90] E. L. Lushnikova, L. M. Nepomniashchich, M. G. Klinnikova, and O. P. Molodykh, "Ultrastructural manifestations of disturbances of cardiomyocyte regeneration after the doxorubicin treatment," Morfologiia, vol. 128, no. 4, pp. 81-84, 2005.

[91] R. Dhingra, V. Margulets, S. R. Chowdhury et al., "Bnip3 mediates doxorubicin-induced cardiac myocyte necrosis and mortality through changes in mitochondrial signaling.," Proceedings of the National Academy of Sciences, vol. 111, no. 51, pp. E5537-E5544, 2014.

[92] I. Salouege, R. Ali, D. Saïd et al., "Means of evaluation and protection from doxorubicin-induced cardiotoxicity and hepatotoxicity in rats," Journal of Cancer Research and Therapeutics, vol. 10, no. 2, p. 274, 2014.

[93] Y. Zhou, X. Kong, P. Zhao et al., "Peroxisome proliferatoractivated receptor- $\alpha$ is renoprotective in doxorubicin-induced glomerular injury," Kidney International, vol. 79, no. 12, pp. 1302-1311, 2011.

[94] S. Ayla, I. Seckin, G. Tanriverdi et al., "Doxorubicin induced nephrotoxicity: protective effect of nicotinamide," International Journal of Cell Biology, vol. 2011, Article ID 390238, 9 pages, 2011.

[95] J. Tao, C. Polumbo, K. Reidy, M. Sweetwyne, and K. Susztak, "A multicolor podocyte reporter highlights heterogeneous podocyte changes in focal segmental glomerulosclerosis," Kidney International, vol. 85, no. 4, pp. 972-980, 2014. 

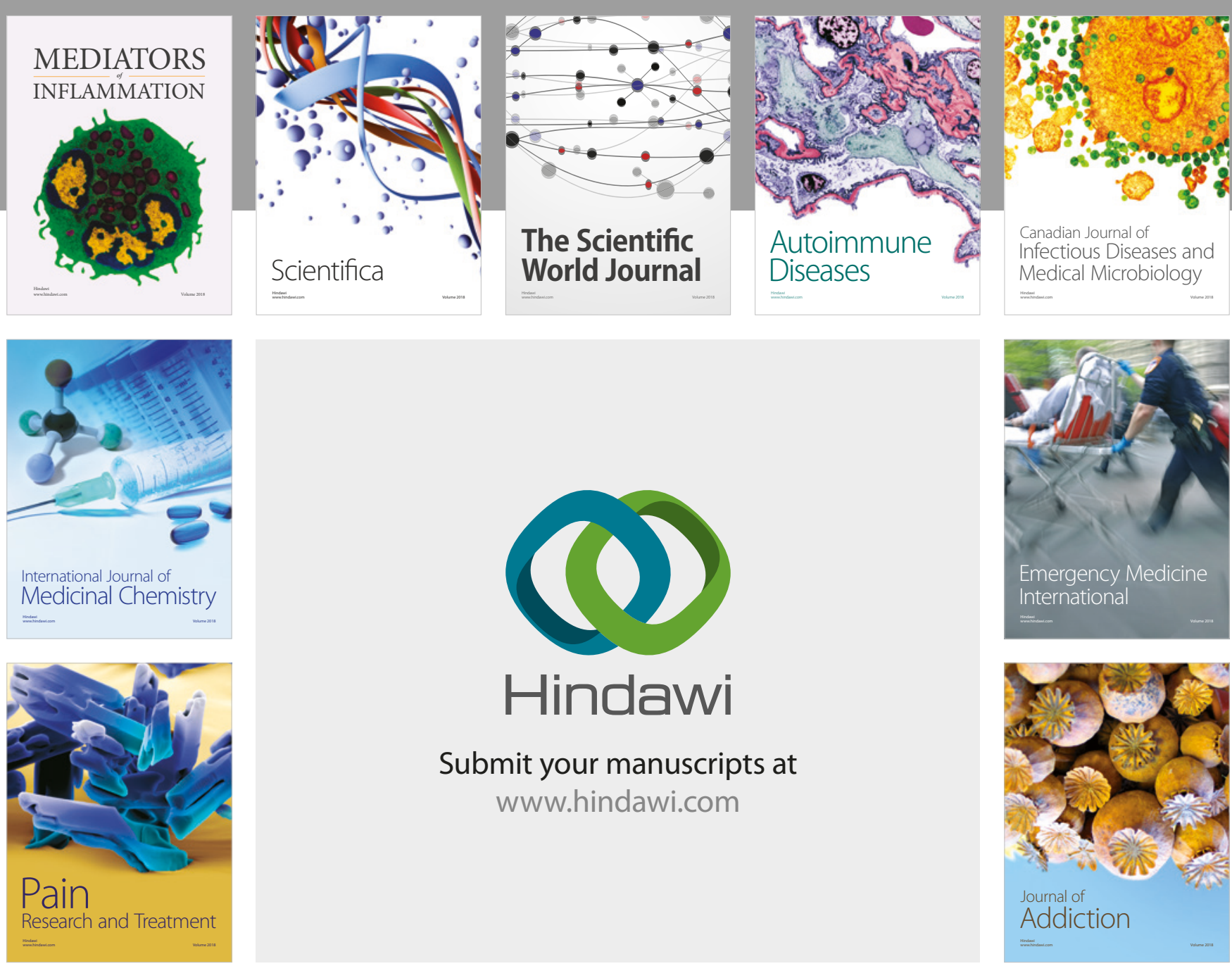

Canadian Journal of
Infectious Diseases and Medical Microbiology

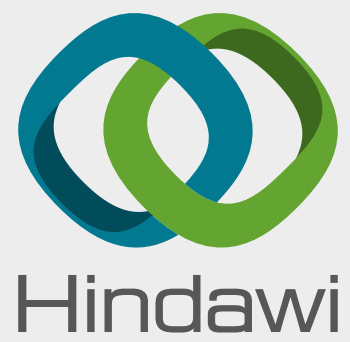

Submit your manuscripts at

www.hindawi.com
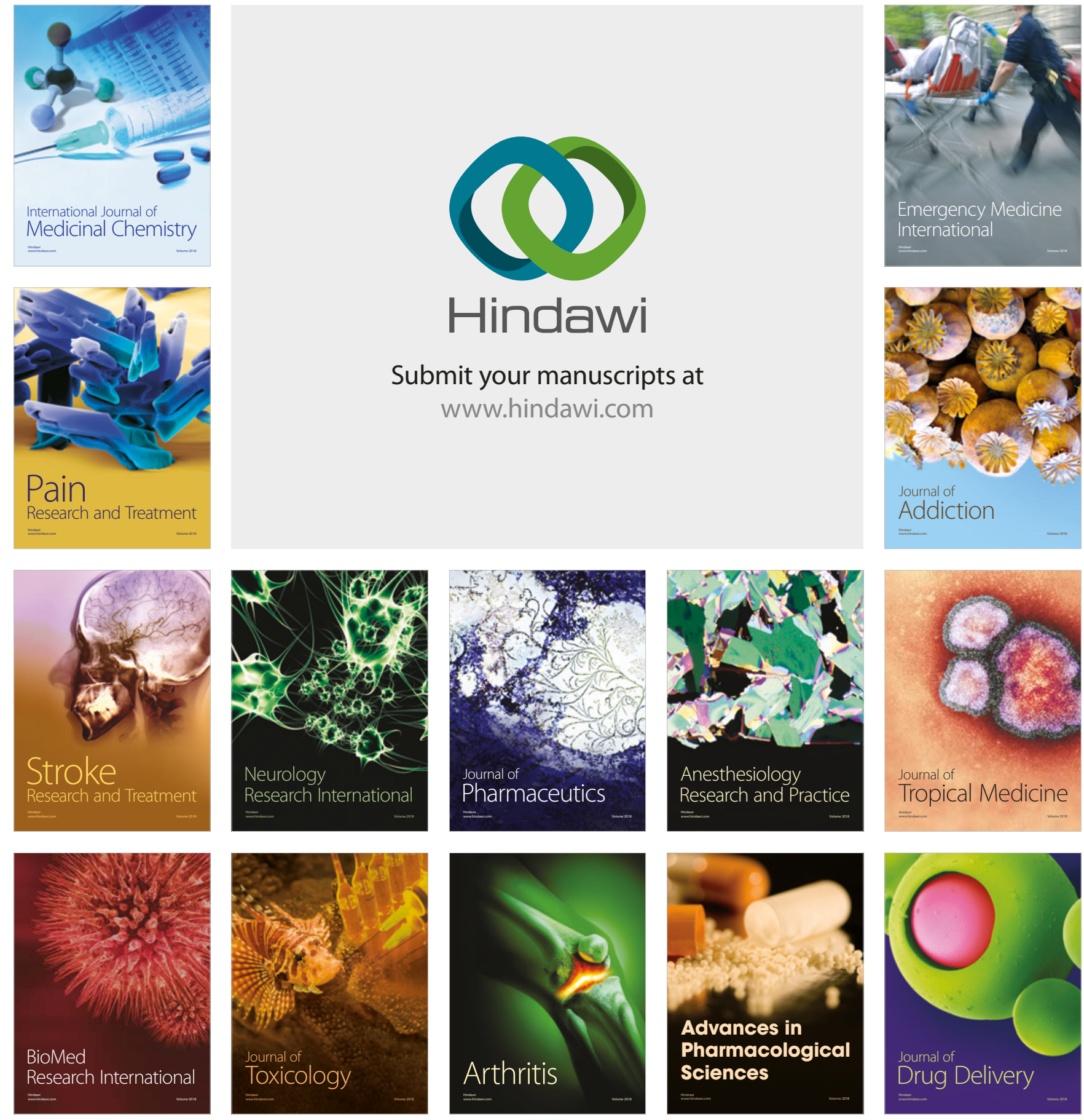